\title{
Review Article \\ Effects of Engineered Nanomaterials on Plants Growth: An Overview
}

\author{
Farzad Aslani, ${ }^{1}$ Samira Bagheri, ${ }^{2}$ Nurhidayatullaili Muhd Julkapli, ${ }^{2}$ \\ Abdul Shukor Juraimi, ${ }^{1}$ Farahnaz Sadat Golestan Hashemi, ${ }^{3}$ and Ali Baghdadi ${ }^{1}$ \\ ${ }^{1}$ Department of Crop Science, Faculty of Agriculture, Universiti Putra Malaysia (UPM), 43400 Serdang, Selangor, Malaysia \\ ${ }^{2}$ Nanotechnology and Catalysis Research Centre (NANOCAT), University Malaya, IPS Building, 50603 Kuala Lumpur, Malaysia \\ ${ }^{3}$ Institute of Tropical Agriculture, Universiti Putra Malaysia (UPM), 43400 Serdang, Selangor, Malaysia
}

Correspondence should be addressed to Nurhidayatullaili Muhd Julkapli; nurhidayatullaili@um.edu.my

Received 16 April 2014; Accepted 5 June 2014; Published 14 August 2014

Academic Editor: Liangti Qu

Copyright (C) 2014 Farzad Aslani et al. This is an open access article distributed under the Creative Commons Attribution License, which permits unrestricted use, distribution, and reproduction in any medium, provided the original work is properly cited.

Rapid development and wide applications of nanotechnology brought about a significant increment on the number of engineered nanomaterials (ENs) inevitably entering our living system. Plants comprise of a very important living component of the terrestrial ecosystem. Studies on the influence of engineered nanomaterials (carbon and metal/metal oxides based) on plant growth indicated that in the excess content, engineered nanomaterials influences seed germination. It assessed the shoot-to-root ratio and the growth of the seedlings. From the toxicological studies to date, certain types of engineered nanomaterials can be toxic once they are not bound to a substrate or if they are freely circulating in living systems. It is assumed that the different types of engineered nanomaterials affect the different routes, behavior, and the capability of the plants. Furthermore, different, or even opposing conclusions, have been drawn from most studies on the interactions between engineered nanomaterials with plants. Therefore, this paper comprehensively reviews the studies on the different types of engineered nanomaterials and their interactions with different plant species, including the phytotoxicity, uptakes, and translocation of engineered nanomaterials by the plant at the whole plant and cellular level.

\section{Nanotechnology: In General}

The nanotechnology process began with the generation, manipulation, and deployment of nanomaterials, representing an area holding significant promise for a wide range of applications [1-5]. Nanotechnology has become a dynamically developing industry, with multiple applications in energy, materials, computer chips, manufacturing, health care, and medical diagnosis $[2,3]$. Products that are derived from nanotechnology are known as nanomaterials [4]. It is believed that there are over 800 nanomaterial products currently available in the market, and it is expected to increase over the next few years [5-7]. Thus, through 2014, it also approximated that an excess of $15 \%$ of all products on the worldwide market would have some type of nanotechnology integrated within their production processes [6].

1.1. Nanomaterials. Generally, nanomaterials refer to a colloidal particulate system, with size ranging from 10 to $1000 \mathrm{~nm}$, possessing unique properties, such as sizedependent qualities, high surface-to-volume ratio, and promising optical properties $[4,5]$. The main categories of nanomaterials are carbonaceous [8], semiconductor, metal oxides [9, 10], lipids [11], zero-valent metals [12], quantum dots, nanopolymer [13], and dendimers [14], with different kinds of features, such as nanofibers, nanowires, and nanosheets (Table 1). The preparation of nanomaterial typically involves a direct and synthetic route that yields particles in the nanosize range, followed by the application of grinding or milling, high pressure homogenization, and sonication to reduce its size $[15,16]$. Meanwhile, the bottom-up process in synthesizing nanomaterials involved reactive precipitation and solvent displacements [17].

It is very important to realize that nanomaterials, due to their enhanced contact surface area, might be poisonous, an effect which might be absent in its bulk counterpart, especially in an open agricultural ecosystem $[9,10]$. Examples 
TABLE 1: Classification of nanomaterials.

\begin{tabular}{lll}
\hline Categories of nanomaterials & Description & References \\
\hline Nanoparticles & $\begin{array}{l}\text { Submicron or even ultramicron size particles obtainable as high } \\
\text { performance radiant resistant materials, magnetic materials, solar } \\
\text { battery materials, packaging materials, and magnetic fluid } \\
\text { materials }\end{array}$ & $\begin{array}{l}\text { Nanometer size long linear material, optical materials, micro } \\
\text { conductors, microfibers, nanotubes of PEEK, PET, and PTFE }\end{array}$ \\
\hline Nanotubes and nanofibers & Films utilized as gas catalyst materials \\
\hline Nanofilm & $\begin{array}{l}\text { Nanometer crystalline materials produced by substantial accuracy, } \\
\text { developing controlled crystallization or nanoparticles }\end{array}$ \\
\hline Nanoblock & $\begin{array}{l}\text { Composite nanomaterials, which use nanosize reinforcements } \\
\text { instead of conventional fibers or particulates }\end{array}$ \\
\hline Nanocomposites & $\begin{array}{l}\text { Polycrystals with the size of 1 to 10 nm and 50\% or more of solid } \\
\text { consists of inherent interface between crystals and different } \\
\text { orientations. The clusters that formed through homogenous } \\
\text { nucleation and grow by coalescence and incorporation of atoms. }\end{array}$ \\
\hline Nanocrystalline solids & {$[18]$} \\
\hline
\end{tabular}

of these cases are solid matrices with nanomaterials that have a nanostructure freely attached to its surface, where it can moderately be expected to break free or leach out once coming into contact with water or air, or when subjected to reasonably foreseeable mechanical forces [14].

\subsection{Engineered Nanomaterials. More than 1300 commercial} nanomaterials, with widespread of potential applications, are currently available $[15-17,19]$. Carbon nanotubes and related materials were discovered in 1985 [8]. By 2011, the annual worldwide production of carbon-based nanomaterials was estimated to exceed 1000 tons, with some of the factory's capacity reaching to 1500 tons per year [20-22]. The first product was shown to be multiwall carbon nanotubes, with concentric cylinders reaching to $10 \mu \mathrm{m}$ in length and 5$40 \mathrm{~nm}$ in diameter [21]. Consequently, a single walled carbon nanotube (SWCNTs) has been synthesized with the assistance of Co/Ni catalyst [23]. This fullerene structure exhibited promising electrical/thermal conductivity and mechanical properties. For example, a single walled carbon nanotube has a strength-to-weight ratio that is 460 times stronger than that of steel $[23,24]$. The behavior of carbon-based nanomaterials is reflective of different environments and conditions [22]. For example, once the carbon-based nanomaterials have been introduced to the human health area, it will group itself with other tubes and rods as high aspect ratio nanomaterials, similar to asbestos [25]. Meanwhile, due to its inherent hydrophilicity, carbon-based nanomaterials tend to precipitate and aggregate in aqueous mediums [21]. Some studies have focused on the surface functionalization of carbonbased nanomaterials, such as the attachment of polyethylene glycol, noncovalent modification, self-assembly, and conjugation of phospholipids, lysophosphtidylcholide, and lysophosphatidylcholine to increase its stability, especially in aqueous suspension [26, 27]. This, in return, increases the application range of carbon-based nanomaterials and its derivatives in catalyst, fuel cell electrodes, orthopedic implants, plastics, battery, super capacitors, water purification system, conductive coatings, adhesive, sensors electronics, composites, aircraft, and automotive industries (Figure 1).
It has been documented that carbon-based nanomaterials such as nanotubes and fullerenes could be degraded under a wide range of conditions, whereby fullerene has a tendency to be taken up by wood decay fungi and metabolized [21-27]. The fullerene nanoparticles would accumulate in microbial cells, followed by eating mechanism of worms, thus increasing the possibility of nanomaterials to be incorporated into the food chain [24].

The next class of engineered nanomaterials is metalcontaining materials, such as metal oxides [9]. The synthesis of metal oxides and metal nanoparticles could be achieved via several routes. Grinding of bulk materials is the usual practice for synthesizing metal oxide nanoparticles $[9,32]$. The range of nanoparticulate metal oxides includes both individual (e.g., $\mathrm{CeO}_{2}, \mathrm{TiO}_{2}, \mathrm{ZnO}, \mathrm{CrO}_{2}, \mathrm{MoO}_{3}$, and $\mathrm{Bi}_{2} \mathrm{O}_{3}$ ) and binary oxides (e.g., $\mathrm{BaTiO}_{2}, \mathrm{LiCoO}_{2}$, and $\mathrm{InSnO}$ ). This series of metal oxide found a wide industrial application. For example, owing to its ultraviolet blocking ability and visible transparency of nanoparticle foam, $\mathrm{ZnO}$ and $\mathrm{TiO}_{2}$ are extensively being used in cosmetics, sunscreen, and bottle coatings [33]. It was reported that in 2005-2010, the production of $\mathrm{ZnO}$ and $\mathrm{TiO}_{2}$ for the application of skin care products reached to 1000 tons per year [34]. Moreover, $\mathrm{CeO}_{2}$ is finding major utilization as a combustion catalyst in diesel fuels to enhance emission quality, as well as in oxygen pumps, gas sensor, solar cells, and metallurgical ceramic/gas applications [35].

\section{Engineered Nanomaterials: In Living System}

The advent of nanomaterials has seen increased production recently, and its interaction with living organisms is a significant cause of concern [10-14, 36]. Manufactured ENs enter living systems through intentional and unintentional releases such as solid/liquid waste streams from manufacture facilities and atmospheric emissions [4]. Nanomaterials can come into contact with living organisms via multiple routes (Figure 2), such as incidental release, direct release from industrial products or processes, as well as commercial products during intended uses that in turn enter the sewer-to-wastewater treatment plants $[37,38]$. 


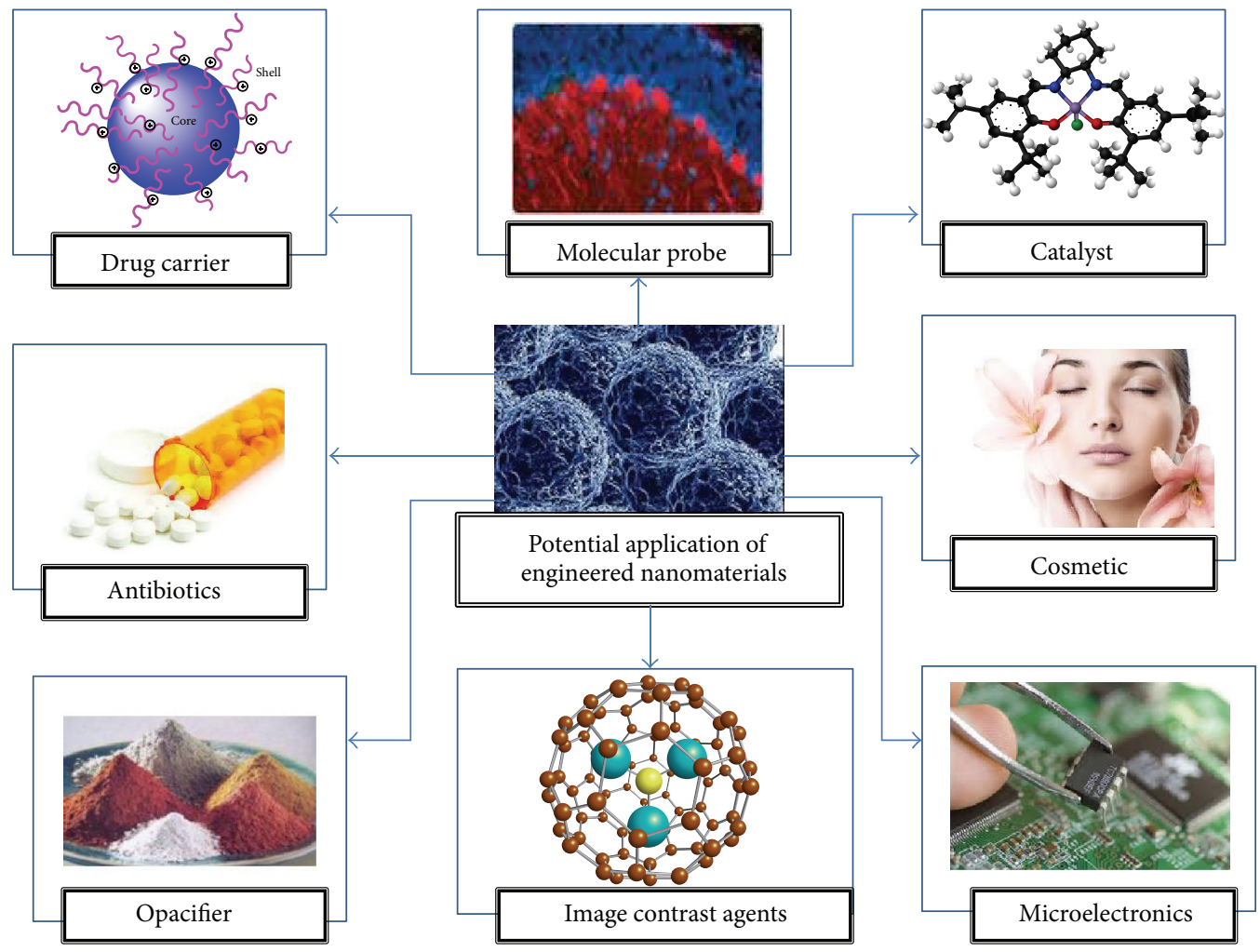

FIGURE 1: List of carbon-based nanomaterials potential applications.

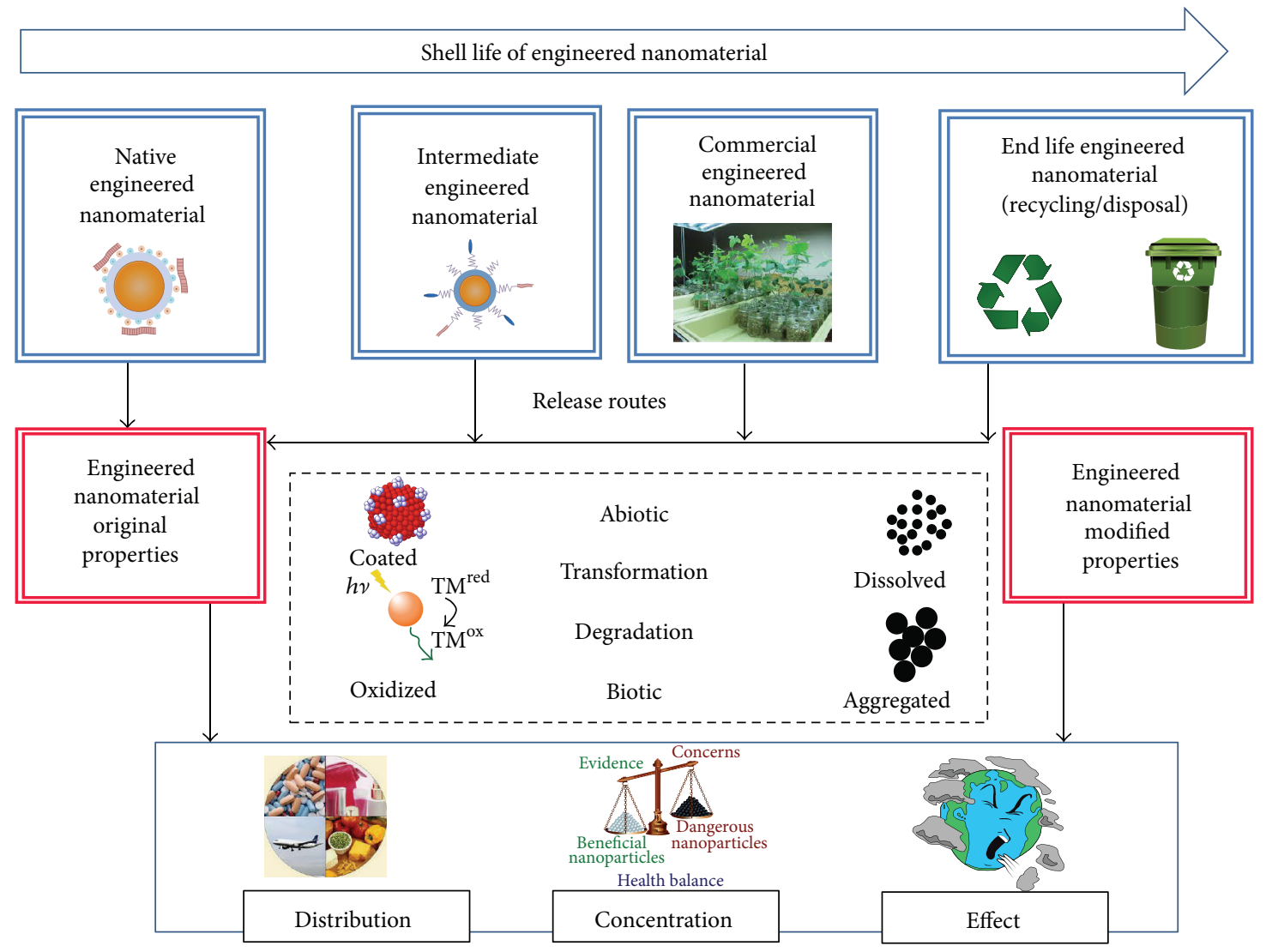

FIGURE 2: Release routes of engineered nanomaterials in living system. 
Its application continues in biosolids from wastewater treatment fields, pesticides applied to agricultural, paints, fabrics, personal health care, and accidental spill of materials during manufacturing, contact during usage of consumer products, and direct infiltration or runoff of excretion from humans or livestock [39]. For example, ENs have been applied to remediate groundwater, where its filtration from stack emissions needs a new generation of nanostructured sorbents for an effective removal [40-42]. Compared to the nanomaterials from diesel emission, the emitted nanomaterials from wastewater would eventually be deposited on the surface water bodies and land despite the fact that the treatment for avoiding aggregation may lead to its buoyancy's increment. Once the nanomaterials reach land, they have the potential to pollute soil, migrate into surface/ground water, and interact with biota. This nanoparticle can also be transported to an aquatic system by rainwater and/or wind runoff. Upon release to water, dispersed nanomaterials are anticipated to behave based on the phenomenon of colloidal science [39]. Generally, colloidal suspensions of ENs are generally unstable, where particles may approach each other close enough for attractive Van der Waals force to become dominant over repulsive electrostatic forces and steric hindrance $[41,42]$. This resulted in particles adhering to each other, followed by sedimentation [40]. Furthermore, natural waters contain other adherent matters such as solid, dissolved, or colloidal materials. In addition, the suspensions of dispersed nanomaterials are stable only under narrow ranges of environmental conditions, where ionic strength, $\mathrm{pH}$, and the presence of natural organic matter should be taken into account $[37,38]$. For example, seawater has a high $\mathrm{pH}$ and ionic strength, thus, electric double layers of colloid particles are smaller compared to freshwater $[39,43]$. This in turn allowed closer interparticle approach, leading to higher aggregations.

Since the last decade, an intensive wealth of acute toxicity studies focusing on biological and ecological effect on shortterm effect of ENs has garnered interest. However, there is still a gap of research interest in the effect on the presence of ENs in living environments. For example, studies on the estimation of appropriate exposure are hampered by the deficiency of knowledge of rates of release or concentrations of nanomaterials in the environment [44]. There is also a lack of knowledge related to the theory of estimating environmental concentrations focusing on the releasing rate $[45,46]$. It has been reported that the existing theory of behavior of chemicals and particulates in the environment is not aligned with the characteristics of nanomaterials. Recently, the theory is only based on the direct measurement and assessment on the existing nanomaterials in living systems, focusing much more on the parameters involved (e.g., acidity, $\mathrm{pH}$, charged ions, and level of organic matter) for the release mechanism [42]. Those theories reported two main conclusions; first, the quantity estimation of nanomaterials in water surface is in accordance to the prediction rather than the actual measurement. Second, nanomaterials could be dissolved, latched onto chemical molecules/ions, clamped, transformed into other chemicals by microorganism, or undergone a mineralization before being 100\% degraded with the dissolution of organic carbon or the generation of $\mathrm{CO}_{2}$ [47-49]. There are some reports that claimed that whether or not it is followed by degradation of the dissolved material, the process of dissolution makes nanoparticles disappear and become less persistent. In principle, the methods measuring $\mathrm{CO}_{2}$ production require a larger amount of test materials [48].

With that in mind, studies that are more extensive need to focus on the possibility of the potential places where ENs are concentrated, agglomerated, or interacted with organic matters [49]. This is important, especially in cases of wastewater treatment, where it will likely be sites for the accumulation of some ENs in sewage. There is also the possibility of bioaccumulations through the concentration of ENs in particular organs $[39,50]$. Through the bioaccumulation process, the aggregation of ENs will end up with sedimentation, where the organism may take up ENs via inhalation or ingestion. Some may also transfer the microorganism across epithelial surfaces (e.g., lining of the lungs, gills, skin, or intestines). Meanwhile, microorganism can also take up ENs via simple diffusion transport across cell membranes, or even after membrane damage [51]. In this case, the transfer mechanism relies on the dispersion, concentration, and dissolving of ENs before ingestion. In addition, some semiconductorengineered nanomaterials could also be concentrated by the waters, which could be directly transferred to the ecosystems' food chains [52-54]. For example, a recent study about the achievable transfer of quantum dots in a simple aquatic food chain has been conducted, and it was reported that nanomaterials could be transferred to rotifers via dietary uptake of ciliated protozoans. Other studies claimed that there is some potential for transferring nanomaterials across food chain levels, depending on the material type and food chain $[54,55]$.

This creates problems for aquatic microorganism, since nanomaterials themselves have an antibacterial or virucidal effect, especially in cases such as silver nanoparticles [56]. For example, studies related to water and land dwelling organisms have shown a wide range of effects on the presence of different ENs on microorganism, invertebrates, and fish. The results so far pointed out the potential for hazardous effects at lethal and sublethal levels (e.g., behavior, reproduction, growth, and development) towards the production of reactive $\mathrm{O}_{2}$ species, inflammatory responses, and cytostatic effects [57-59]. This is supported by some of the studies on the potential effects on the movement of ENs to embryos, accumulation, and food chain transfer [58].

With that in mind, some issues should be addressed and highlighted concerning the presence of ENs in the living system. The issues ranged from the behavior of nanomaterials manufacturers in the environment, the stability of ENs, effect on aquatic/sedimentary biota not being similar to nonnanomaterials of the same materials, and suitable protection of the ecosystem while permitting the advantages that nanotechnology offers to be fully developed [58-61]. This started with the knowledge of colloidal science, which could provide evidence of the physical and chemical characters of nanomaterials in the receiving environment [48-51]. Generally, small particles tend to agglomerate or aggregate 
relative to other colloidal, which accounts for its particulate being present in the environment [34]. In the context of the environment, ENs may be present and cannot be disassociated by either dissolution or agglomeration [44]. As far as we can tell, there are no peer-reviewed publications on the concentration of ENs in environmental compartments, such as surface water or soil [35, 37-41]. Indeed, the quantity estimation of ENs is based on its predicted rather than the actual values, which could be considered suitable metrics of the accurate measurement of ENs in living system risk assessment not being finalized and still under discussion [32]. Several considerations should be taken into account in the assessment effect of nanomaterials in living systems, where the exposure concentration/doses should be realistic. In this case, the assessment should not only cover the free nanoparticle form, but also all physical and chemical species, aggregated matter, and associated/deposited matter with other organic compounds. This would have influenced ENs bioavailability, which will in turn determine the biological uptakes.

\subsection{Engineered Nanomaterials in Agriculture. Engineered nano-} materials research and development, in agricultural applications, probably facilitated and framed the next stage of development of genetically modified crops (GMCs), animal production input, biocides, and precision farming system [59-64]. Similar to other technologies, low-cost ENs and field application technologies are required for their applications in agriculture [1-5]. Nanotechnology is the result of the improvement associated with a variety of economical applications for superior plant growth. Applications of ENs motivate earlier plant germination as well as enhance plant production (Figure 3 ).

Nanoagriculture utilizes nanotechnology to improve the yield of plants for food, fuel, and other uses. Researchers report a big gap in knowledge about the effects of nanoparticles on rice, tomatoes, corn, and other food crops [6365]. The build-up and uptake of ENs differs and these kinds of components mainly rely on the type of plant, the chemical composition, and the size of ENs [66-68]. Some plants are capable of uptaking and accumulating engineered nanomaterials. The interaction of plant cell with the ENs leads to the modification of plant gene expression and associated biological pathways, which eventually affect plant growth and developments [67-69]. The effects of ENs on different plant species can vary greatly with plant growth stages, method, and duration of exposure and depend on the ENs shape, size, chemical composition, concentration, surface structure, aggregation, and solubility [68].

To our knowledge, the first report relevant to the effects of bulk and ENs on Sage (Salvia officinalis L.) is in [69]. Nanomaterials improved seed germination in plants but can have contrary effects on others $[63,64]$. In these instances, studies on ENs aspects are on the nanoparticles dosage in the various mediums, their chemical and physical properties, the mechanisms permitting them to pass through cellular membranes and cell walls. The specific properties, which might be in connection with positive and negative effects of

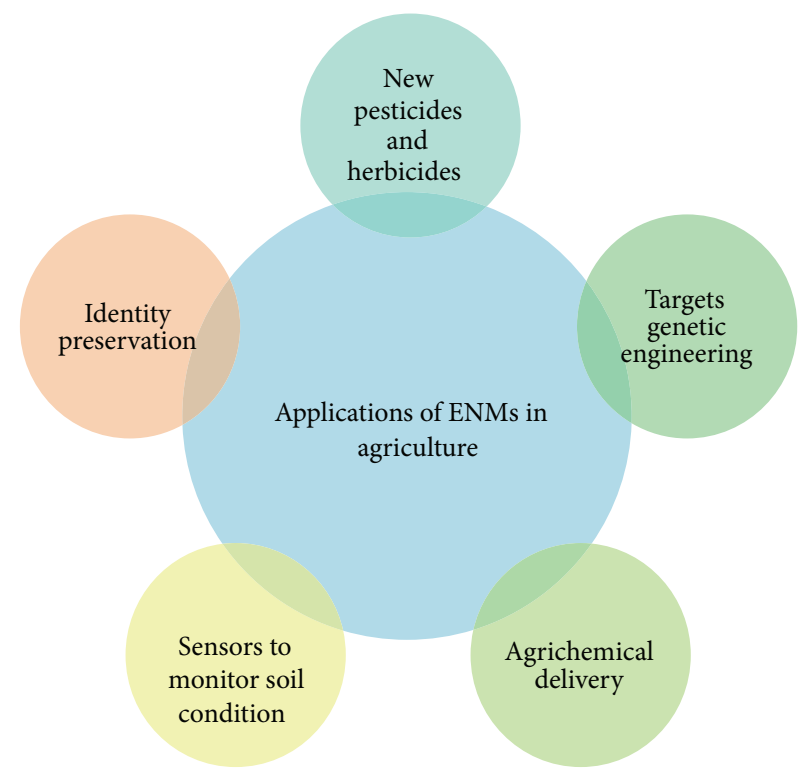

FIGURE 3: General application of engineered nanomaterials in agricultural.

nanoparticles and the mechanism underlying nanoparticles trophic transports are necessary as well [65]. Moreover, the existing application methods need to be reviewed for improved efficiency of nanomaterials on future targets. The necessity of further studies on the possible risks related to the use of nanomaterials and their potential adverse effects is needed [60-62].

Research indicates that extended amounts of ENs are highly toxic to aquatic life, bacteria, and human cells in vitro. At the nanoscale, even normally benign substances may become hazardous. According to the particle physics and studies of fine atmospheric contaminants, ENs are usually in the size range that stays suspended for days to weeks if released into the air [54-56]. ENs are inhaled and collected in all regions of the respiratory system of the plant. Because ENs is small, they follow airstreams more easily than larger particles are simply collected and taken in standard ventilated enclosures [5-9]. Therefore, a particular concern is the ability of the nanoparticle directly taken up by individual cells and cell nuclei, especially through the respiratory system. Bioaccumulation is another topic of concern $[10-12,36]$. As the properties of materials at the nanoscale variable are poorly understood, it is not possible to provide a generic assessment of health and environmental risks [53-55].

Therefore, the interaction associated with plant cell and ENs led to the modification of plant gene expression. It connected biological pathways, which eventually affect the plant growth and development. This is due to the unique properties of ENs that can modify their physicochemical properties and give different effects on plant growth, depending on nanomaterials surface structure, size, shape, chemical composition, concentration, solubility, and aggregation [63]. Hence, ENs ought to be designed to have all necessary properties such as effective concentration with high effectiveness, stability, and solubility, time-controlled release in 


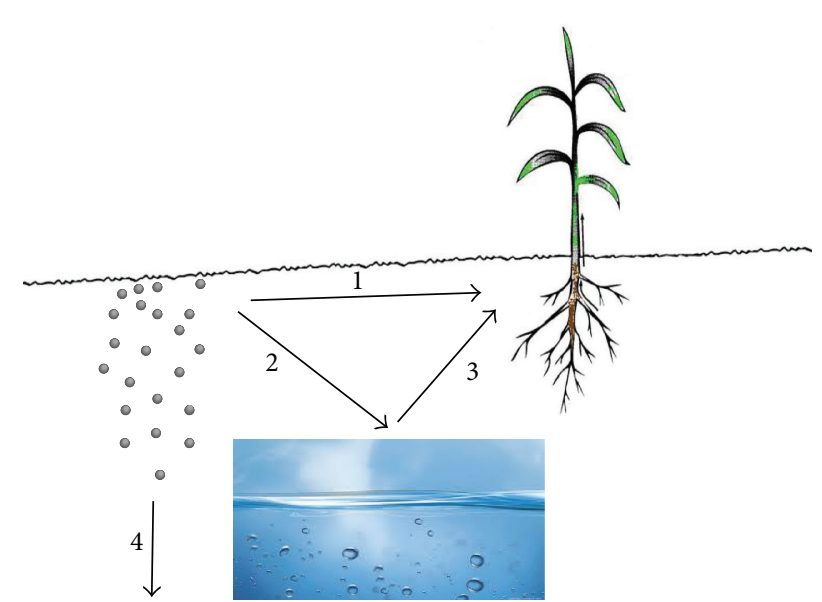

FIGURE 4: Interaction of engineered nanomaterials in the environment. (1) Engineered nanomaterials absorbed directly to plant root. (2) Engineered nanomaterials mixed with water medium. (3) Engineered nanomaterials mixed with water and transferred to plant. (4) Engineered nanomaterials stayed in the soil.

response to certain stimuli, enhanced targeted activity, and less toxicity with safe and easy mode of delivery to avoid repeated applications $[67,69]$. The vast majority of research works done for each different nanomaterials and product in agriculture is thereof to investigate its potential toxicity before its use could consider safe.

\section{Engineered Nanomaterials: On Plant Growth}

The possibility of plants interacting with ENs is increased with the application of its production and application in the variety of instruments and goods. Underneath particular growing environments, plants may possibly absorb essential and nonessential elements, which to certain concentration, might result in toxicity [70-72]. It has been documented that, toxic elements with no known function in biological systems usually accumulate in plant tissues and cause some lethal effect for nontolerant species [55, 71]. ENs can reach plants through direct application, accidental release, contaminated soil/sediments, or atmospheric fallouts, which results in a significant negative effect on food crops and food chains (Figure 4).

It is worse when these toxic elements are transferred from plants to consumers. Research studies on selenium have found that selenium-laden plants can be used to supply selenium deficiencies in ruminants and other animals, even at very narrow and low deficiencies and toxicities $[63,72]$. This has been supported by other studies that focused on the toxicity of various types of plants, including radish (Raphanus sativus), corn (Zea mays), lettuce (Lactuca sativa), cucumber (Cucumis sativus), rape (Brassica napus), and many more $[69,70]$. However, the biodegradation screening method of measuring dissolved on toxicity of both carbon and metalbased nanomaterials is inapplicable. Indeed, most studies concentrated on the uptake, accumulation, translocation, and biotransformation of ENs.

3.1. Carbon Based Engineered Nanomaterials: On Plant Growth. A wide production of carbon-based nanomaterials has led to its potential release in living systems, either intentionally in discharges, or unintentionally in spillages, and greater possibilities of the adverse environmental effects [8]. Among carbon-based nanomaterials, the most studied materials are fullerene $\mathrm{C}_{70}$, fullerol $\left(\mathrm{C}_{60}(\mathrm{OH})_{20}\right)$, and carbon nanotubes. As carbon-based nanomaterials are considered highly hydrophobic with the tendency to aggregate, it could be expected to settle in the living system [73]. This hydrophobic property would enhance the carbon-based nanomaterials' capability to interact with many organic substances. Thus, the only low surface friction of carbon nanotubes is required to assist the flow of organic substances into the cytoplasm [74]. Some edible plants can take up some carbon-based nanoparticle, with specific uptake mechanism and accumulation. Properly functionalized ENs provided better penetration through the cuticle. This in turn allows for a slow and governed discharge of active ingredients on reaching the target weed. For instance, appropriately functionalized lipophilic nanosilica gets absorbed into the cuticular lipids of insects by physisorption, damages the protective wax layer, and induces death by desiccation.

3.1.1. Fullerene: On Plant Growth. It has been reported that the presence of fullerene in the form of black aggregates is more plentiful in seeds and roots compared to the leaves and stems for rice seeds [73-75]. However, in mature plants, more robust translocation from the roots of the aerial part of the plant is observed. Thus, fullerene aggregates were mostly present in or near the stems vascular system and leaves, whereby the roots have been devoid of fullerene [74]. The aggregation of fullerene in leaves indicated that they followed the transmission route of nutrients and water through the xylem [76]. It is believed that the individual fullerenes nanoparticle entering the plant roots through osmotic pressure, capillary forces, and pores in the cell walls by the intercellular plasmodesmata, or by means of the greatly regulated symplastic routes $[77,78]$. Only the fullerene particles with a diameter of less than the pore diameter of the cell wall could simply pass through and reach the plasma membrane [74].

3.1.2. Fullerol: On Plant Growth. The small size and hydrophobicity properties inducing a permeability of fullerol through the cell wall pores in the plant cell suspension leads to minimal uptake of the nanoparticles [79]. Consequently, the fullerol have accumulated at the interface between the cell wall and plasma membrane [77]. This accumulation also occurred between adjacent epidermal cell walls, showing its apoplectic mode of transport in the plant tissues $[77,79]$.

3.1.3. Carbon Nanotubes: On Plant Growth. Carbon nanotubes (CNTs) may have possibly single or multiple layers of carbons established in a cylinder [80-84]. CNTs behave as 
fibers, with its properties very different from bulk carbon or graphite [81]. Thus, CNTs possess excellent tensile strength and are possibly the strongest, smallest fiber known [82-84]. Most studies are increasingly carried out in order to obtain the uptake and transport mechanism of carbon-based nanomaterials into intact plant cells [85-87]. There is proof that CNTs could translocate to systemic sites, such as fruits, leaves and roots, which could involve a strong interaction with the cells of the tomato seedling. This resulted in significant changes in total fruits, leaves, and roots gene expression [86]. CNTs have phytotoxic effects on plant cells due to aggregation and causes cell death in a dose dependent manner [73]. Cell death is demonstrated by electrolyte leakage and the swelling of the cell plant.

Theoretically, single wall carbon nanotube is too large to penetrate the cell wall. However, the evidence of an endocytosis-like structure of the plasma membrane in an Arabidopsis thaliana leaf cell indicates the existence carbon nanotubes and is extremely relevant to guide for additional studies with other edible plants $[88,89]$. Then, researches with cell suspensions of Nicotiana tabacum cv. Bright Yellow found that the water-soluble single wall carbon nanotube with a length of less than $500 \mathrm{~nm}$ has penetrated the intact cell wall and membrane over fluidic phase endocytosis [90, 91]. Due to its small size, carbon nanotubes tend to interact with the polysaccharides and proteins in the cell wall and elicit hypersensitive retorts mimicking plant pathogens, leading to cell mortality [80-83]. This is supported by the recognition of noncovalent interactions involving rice mortality and carbon nanotubes. Thus, CNTs could possibly improve root growth of cucumbers (Cucumis sativus), onions (Allium cepa), and nanotube sheets formed by both functionalized-CNTs and nonfunctionalized CNTs on root surfaces, but none entered the roots $[92,93]$. Though CNTs were discovered to diminish root growth in tomato plants, recent works reported that CNTs penetrated tomato seed coat and significantly enhance seedling growth and seed germination rates [93-95].

3.1.4. MWCNTs: On Plant Growth. Multiwalled carbon nanotubes (MWCNTs) are $1 \mathrm{~mm}$ long and $20 \mathrm{~nm}$ in diameter [96-99]. MWCNTs are taken up by the seeds and roots system via the creation of new pores and water uptake in order to develop tomato seedlings $[100,101]$. In this case, MWCNTs are visualized to be on the root surface before eventually piercing the epidermal and root hair cell walls and cap of the seedlings [102]. Furthermore, some studies described that MWCNTs permeate tomato seeds and boost the germination rate by improving the seed water uptake [101]. The MWCNTs elevated the germination of seed to up to $90 \%$ in 20 days compared to $71 \%$ in the control sample and the plants' biomass [103]. Other researches pointed out that the cell walls of rice cell suspension restrict the entry of the MWCNTs into the cellular cytoplasm, forming black clumps that strongly wrap around and associate with the cells [100]. The presence of the clumps, with an increase in the concentration of carbon nanomaterials, would increase in both size and number [101]. This hypersensitive response is thought to be in charge of preventing the entry of MWCNTs through the plant cell walls [101-103]. For example, the seeds treated with MWCNTs showed a few aggregate nanotubes in the vascular system, and none in the tissues. Meanwhile, in the zucchini species, there are no negative effects noticed on seed germination and root elongation within the examined range of MWCNTs [104].

3.1.5. SWCNTs: On Plant Growth. The dimension of typical single walled carbon nanotube (SWCNTs) is about 1 to $2 \mathrm{~nm}$ in diameter and $0.1 \mu \mathrm{m}$ in length $[24,105,106]$. Some studies indicate that the surface modifications of carbonbased nanomaterials increased its widespread, dispensability, and water column stability [107-111]. Contrarily, no uptake of SWCNTs and its functionalized roots of cucumber seedling are found after treatment for $84 \mathrm{~h}$. In the form of nanotube sheet, the SWCNTs were found adhered to the external surface of the main and secondary roots $[112,113]$. However, current results are insufficient to determine the translocation of SWCNTs from the root systems to the aerial parts of the plant [110-116].

3.1.6. Graphene: On Plant Growth. Graphene is a two dimensional crystalline allotrope of carbon, which can be described as a one atom layer of graphite. At high concentrations of graphene $\left(1000 \mathrm{mgL}^{-1}\right)$, the root hair growth of red spinach and cabbage decreased compared to the control plant [117119] (Figure 5). This is due to the accumulation of graphene using $\mathrm{H}_{2} \mathrm{O}_{2}$ visualization, together with visible signs of necrotic damage lesions and proof of a massive electrolyte leakage, indicating an oxidation stress mechanism $[28,118$, 120].

For example, intracellular reduction oxidation system probably has an essential function in the induction of cell death induced by graphene [28] (Figure 6). It described the accumulation graphene as leading to cell death, shown by electrolyte leakage from cells [119]. Via graphene treatment, the root surface area of cabbage significantly improved, and it may be that an excess of graphene resulted in the swelling in Origanum vulgare and Origanum [117, 118]. Graphene is known as inducing phytotoxic effects in plant cells due to the accumulation mechanism. This causes cell death and the accumulation in a dose-dependent manner $[121,122]$. There is certainly proof that graphene could translocate to systemic sites, such as fruits, roots, and leaves, which engage in a strong interaction with the cells of tomato seedlings, leading to substantial modifications in total gene expression in fruits, leaves, and roots and exerting toxic effects [123-126].

With that, it is unexpected to find the toxic effects of graphene on terrestrial plant species, in tomato, cabbage, and red spinach $[124,125]$. The similar growth pattern observed in tomato, cabbage, and red spinach using graphene nanomaterials was reported in $[117,124,127]$. At higher concentrations of graphene $\left(1000 \mathrm{mgL}^{-1}\right)$, the root hair growth of red spinach and cabbage compared to control plants was reduced [117] (Figure 7).

Overproduction associated with the accumulation induced by graphene could produce substantial plant growth inhibition, and biomass reduction reported that 


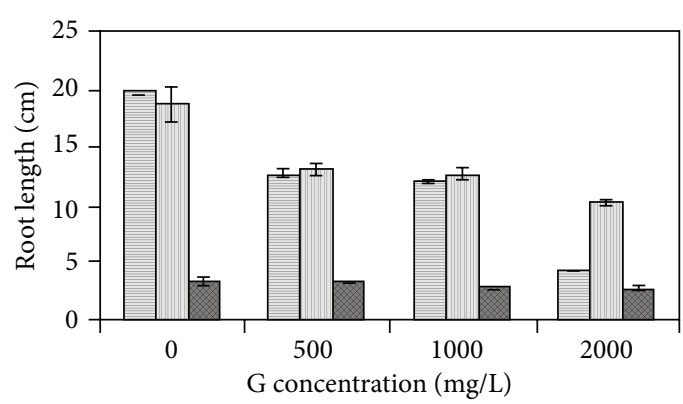

(a)

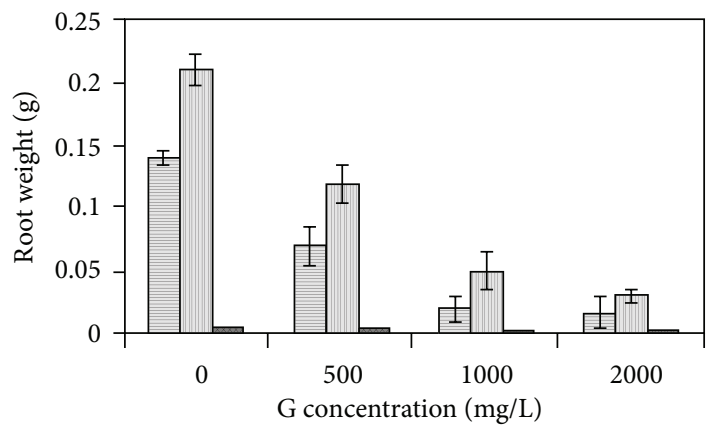

(c)

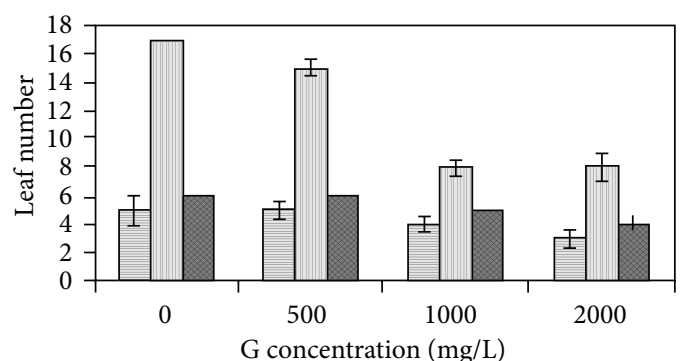

Cabbage

Tomato

Red spinach

(e)

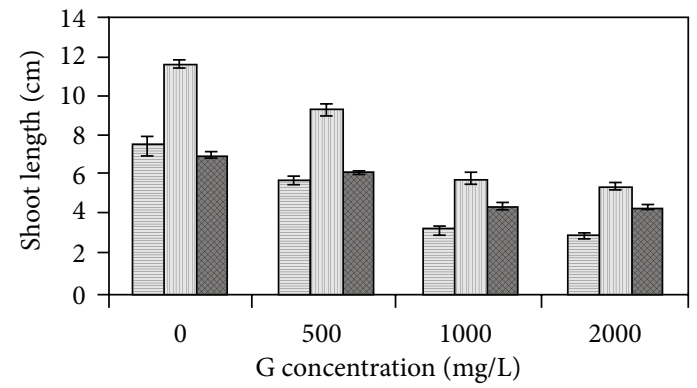

(b)

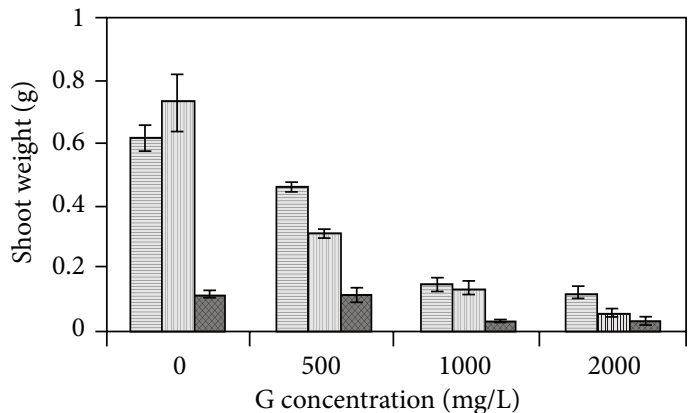

(d)

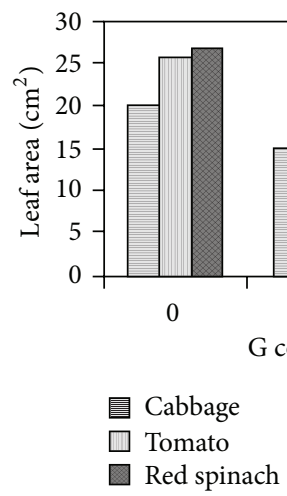

(f)

FIGURE 5: Effect of graphene $(G)$ on of red spinach, cabbage, and tomato seedlings. 21 days seedlings growth on Hoagland media with graphene $\left(0,500,1000\right.$, and $\left.2000 \mathrm{mgL}^{-1}\right)$ were utilized for all measurements. (a) Root length, (b) shoot length, (c) root weight, (d) shoot weight, (e) leaf number, and (f) leaf area [28].

the production of accumulation could be a main factor in the toxicological effects of nanostructured materials [128]. Declaration of accumulation production by means of $\mathrm{H}_{2} \mathrm{O}_{2}$ visualization in addition to visible signs of necrotic damage lesions and evidence of a massive electrolyte leakage all indicated an oxidative stress mechanism mediated through the necrotic pathway, which requires further study $[117,127]$. The assessment of graphene toxicity targets terrestrial plant species $[125,126]$. It applies a prolonged exposure period with different concentrations to measure potential risks.

3.2. Metal and Metal Oxide Nanomaterials: On Plant Growth. Estimates for the production of metal/metal oxide nanoparticles revealed that the quantities produced will probably rise from 2000 tons in 2004, to over 58,000 tons yearly between 2011 and 2020 [129-132]. Metal/metal oxide nanoparticles display size dependent properties, such as fluorescence, photocatalytic degradation, or magnetism, which has biotechnological applications in soil remediation, sensor development, and agrochemicals $[130,131]$. In natural living systems, the effect of metal/metal oxide by plants is expected to depend largely on the chemical properties, colloidal properties such as sediments, soil or sludge, and organic content $[133,134]$. The most studied metal-based nanomaterials are $\mathrm{TiO}_{2}, \mathrm{CeO}_{2}$, $\mathrm{Fe}_{3} \mathrm{O}_{4}$, and $\mathrm{ZnO}$ nanoparticles. Indeed, $\mathrm{Fe}_{3} \mathrm{O}_{4}$ nanoparticle induces some stability effect on aquatic suspensions of fullerene and carbon nanotubes. It has been documented that the effect of humic acids and varying $\mathrm{pH}$ can combine the effects on the fate of $\mathrm{Fe}_{3} \mathrm{O}_{4}$ nanoparticle by increasing $\mathrm{pH}$, 


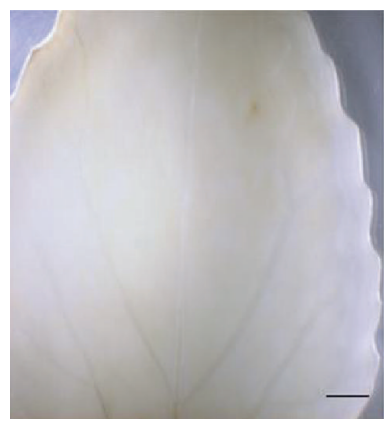

(a)

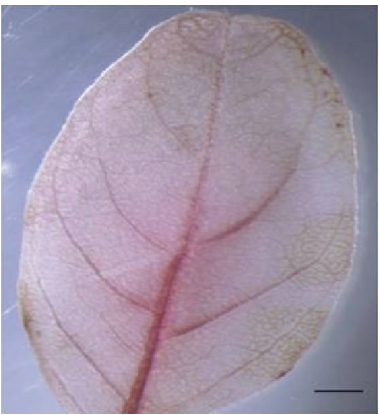

(e)

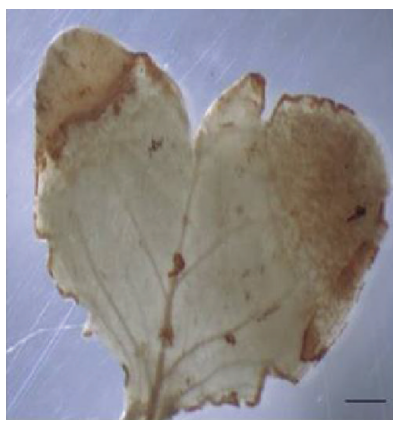

(b)

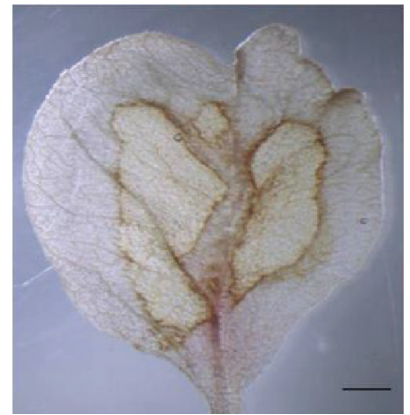

(f)

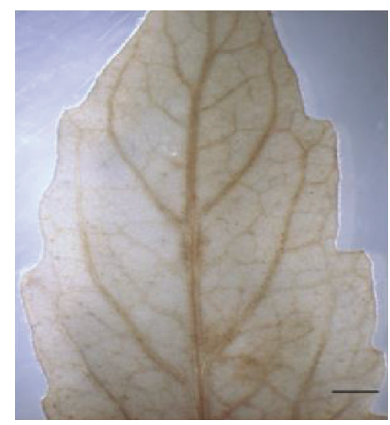

(c)

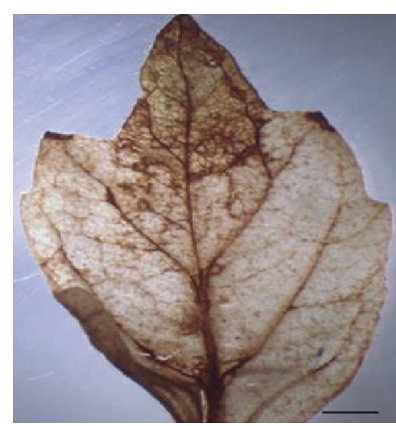

(d)

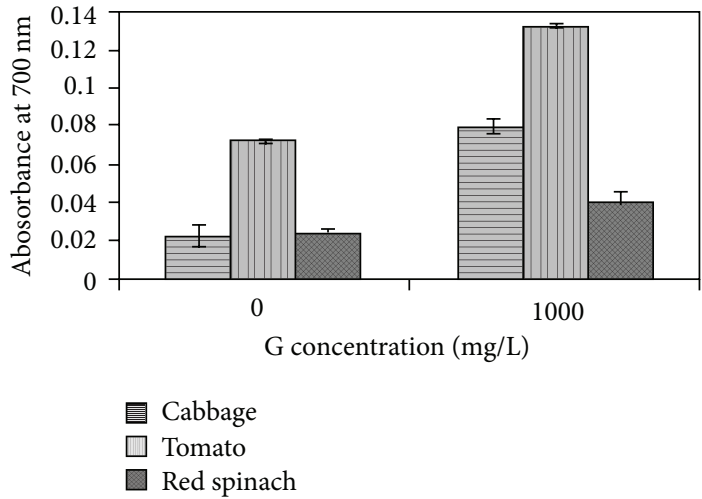

(g)

Figure 6: Effects of graphene $(\mathrm{G})$ on accumulation of $\mathrm{H}_{2} \mathrm{O}_{2}$ in leaves tested by means of the ROS-sensitive dye DAB of red spinach, cabbage, and tomato seedlings. 21 days leaves treated with or without $1000 \mathrm{mgL}^{-1}$ graphene were utilized for all measurements. (a), (c), and (e) are cabbage, tomato, and red spinach leaves without graphene, respectively. (b), (d), and (f) are cabbage, tomato, and red spinach leaves with graphene $\left(1000 \mathrm{mgL}^{-1}\right)$, respectively. The brown staining shows the formation of a brown polymerization product when $\mathrm{H}_{2} \mathrm{O}_{2}$ reacts with DAB. (g) Effect of graphene $\left(1000 \mathrm{mgL}^{-1}\right)$ on the accumulation of $\mathrm{H}_{2} \mathrm{O}_{2}$ in treated leaves as measured utilizing DAB [28].

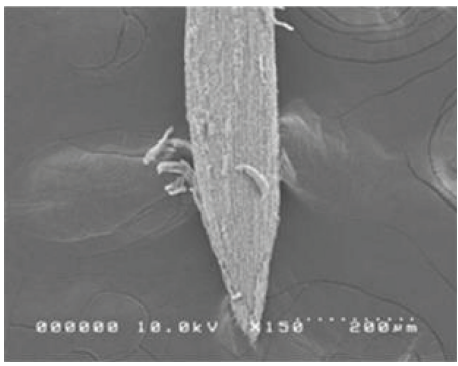

(a)

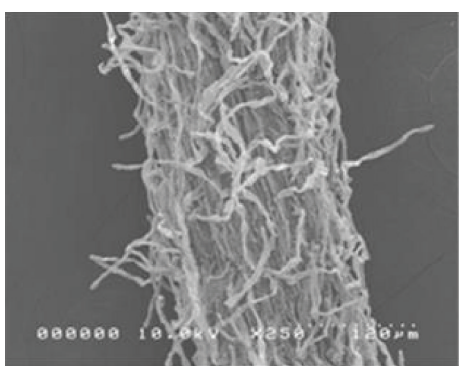

(d)

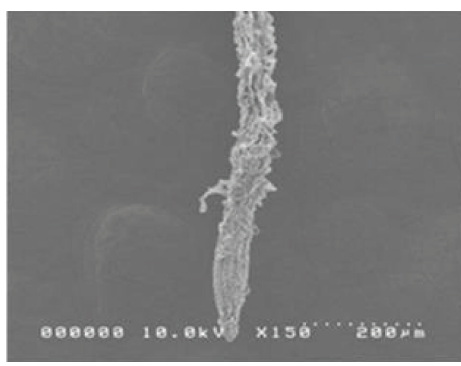

(b)

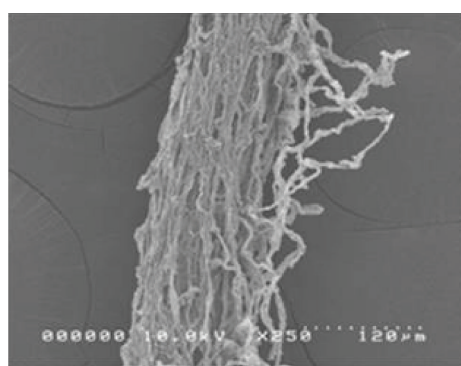

(e)

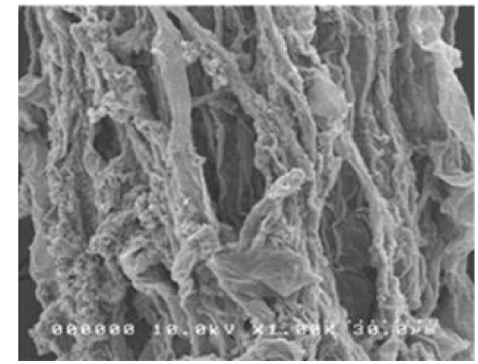

(c)

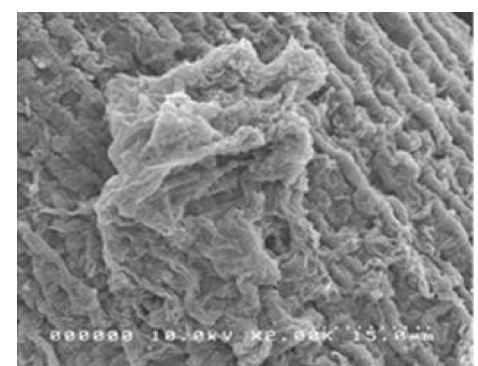

(f)

FIGURE 7: Behavior of graphene $\left(1000 \mathrm{mgL}^{-1}\right)$ on the root surface of tomato seedlings grown in Hoagland medium. (a, d) SEM image of the untreated control of tomato root elongation and root hair zone, respectively. (b) Root elongation zone of tomato root and (c, e, and $\mathrm{f}$ ) showing surface detachment and aggregates of $\mathrm{G}$ on the tomato roots surface treated with $\mathrm{G}$ [28]. 
resulting in a higher level of aggregation. A similar effect was recently shown for $\mathrm{CeO}_{2}$.

Metal nanoparticles, under low concentration conditions, play a key role at the limit of plant tolerance in the development of plants [132]. If plants absorb an excess of metals, toxic effects can obvious, including the decrease of growth and irregularities in cell division [129-131]. In this case, excess metal nanoparticles, acting as cofactor for enzymes, are involved in the formation of intermediate metabolites. However, the response of plants to metal nanoparticle varies with the nature of the metal, type of plant species, and the stage of growth.

3.2.1. Au: On Plant Growth. Gold ( $\mathrm{Au})$ is categorized as a harmful substance, and the toxicity of Au in many organisms has been reported in ionic or dissolved form [135-138]. The toxicity of Au has been harnessed in the form of $\mathrm{Au}$ nanoparticles to act as antibacterial agents in biocide coating, soap, toothpaste and shampoo, and is the most prevalent nanoparticle in over 25 consumer products [136, 137]. The production and the usage of Au nanoparticles in the environment and its potential discharge to the environment might cause severe toxicity problems in the long run [139141].

For example, Brassica juncea, Medicago sativa showed an increase in Au uptake, with a conforming improvement in the substrate of Au concentration and exposure time [142144]. The Au nanoparticles located in the nucleus and the applications of defamation suggested at both species are regarded as hyperaccumulators of $\mathrm{Au}$ nanoparticles [145147]. Additionally, it is documented that Au nanoparticle are transported inside the cells through plasmodesmata. Transmission electron microscope images of rice roots revealed that various $\mathrm{Au}$ particle sizes are deposited inside the root cells in the form of vacuoles [143]. The cell damage occurred due to penetrations of large Au nanoparticles entering via small pores [142-145]. Au nanoparticles are reported to disrupt the root tip cells of onion (Allium cepa), thus damaging the cell division process by causing the formation of chromatin bridge, cell disintegration, and stickiness [148].

3.2.2. Ag: On Plant Growth. Potential applications of silver (Ag) nanoparticles in biomedicine include imaging applications and chemical sensing. Ag nanoparticles are synthesized using various methods, chemical, electrochemical, photochemical, laser ablations, and others [10]. Although bulk Ag is considered "safe," Ag nanoparticles need to be examined for environmental impact and biocompatibility if they are to be produced for in vivo usage on a large scale [149151]. Furthermore, exposure data had shown Ag nanoparticle to be prevalent in the environment, at low but increasing concentrations, with estimation of up to 0.1 and $2.9 \mathrm{mgL}^{-1}$ at the sludge and surface water [152-154]. Thus, some reports suggested the biological effect of Ag nanoparticles might be seen at concentrations of up to 1000 times lower than that for the dissolved $\mathrm{Ag}^{+}$ions [153]. Furthermore, some results from the research proved that the toxicity of $\mathrm{Ag}$ nanoparticle is minor at exposures as low as $5 \mathrm{mgL}^{-1}$, with greater inhibitions of growth $[152,154,155]$. It is clear that Ag nanoparticles within the environment pose a potential risk to greater plants, and therefore, the function of ecosystems [153-156]. Ag nanoparticles show adverse effects on seed germinations, root, and shoot growth at concentrations of $4500 \mu \mathrm{gmL}^{-1}$, $6000 \mu \mathrm{gmL}^{-1}$, and $3000 \mu \mathrm{gmL}^{-1}$ on species of rice (Oryza sativa), Mung bean (Vigna radiata), and Chinese cabbage (Brassica campestris), respectively [157-159].

Furthermore, Ag nanoparticles with sizes of approximately $40 \mathrm{~nm}$ have the potential to cause toxic effects in Chlamydomonas reinhardtii algae and Cucurbita pepo [160164]. In the case of Cucurbita pepo, Ag nanoparticles induced 4.4 to 10 times more reductions in biomass and transpiration rates, rather than bulk sizes $[29,164-167]$. Meanwhile, the limits of uptake and the distribution of Ag nanoparticles have been studied for Medicago sativa and Brassica juncea species [29, 168-177] (Figure 8).

Various groups have examined the cellular uptake and cytotoxicity of Ag nanoparticles in plant systems. Research on the seed germination and the root growth of zucchini plants in hydroponic solution modified with Ag nanoparticles displayed no negative effects, whereas reductions in plant biomass and transpiration were observed on prolonging the plants' growth in the presence of Ag nanoparticles. The genotoxic and cytotoxic impacts of Ag nanoparticles were studied, utilizing the root tips of onions. Results of $\mathrm{Ag}$ nanoparticles impaired the stages of cell division and caused cell disintegration $[162,164]$. There are some reports on greater toxic effects in the Chlamydomonas reinhardtii algae exposed to $\mathrm{Ag}$ nanoparticles as $\mathrm{AgNO}_{3}$, at the particle size of $40 \mathrm{~nm}[164]$.

There are some studies concentrated on effect of $\mathrm{Ag}$ nanoparticle on aquatic plant [168-170]. The studies reported on usage of Lemna minor L. clone St to study the phytotoxicity of Ag nanoparticles. The final results demonstrated that the inhibition of plant growth was apparent after exposure to a wide range of $\mathrm{Ag}$ nanoparticle (20 to $100 \mathrm{~nm}$ ), even at low concentrations $\left(5 \mathrm{mgL}^{-1}\right)$ [169-171].

The effects of Ag nanoparticles have also been assessed in many different researches involving plant mediums [178]. The studies focused on soil nematodes, soil microbial community, and other related concerns. It has documented that $\mathrm{Ag}$ nanoparticles with sizes of up to $29 \mathrm{~nm}$ employed visible reduction effects on the germination of lettuce seeds and cucumber, but no toxic effect has been observed and reported on the reduction germination of barley and ryegrass exposed to $\mathrm{Ag}$ nanoparticles. Ag nanoparticles with sizes $<100 \mathrm{~nm}$ have also shown to reduce the biomass and transpiration of pumpkin (Cucurbita pepo) [160]. It reported increased Ag nanoparticles content in the common grass Lolium multiflorum, with increasing Ag nanoparticles' concentration. Additionally, the cytological effects of onion (Allium cepa) have been reported to include disturbed metaphase, stickiness, chromatin bridge, and other effects. The majority of nanotoxicological researches showed on plants thus far have utilized alternative methods rather than soil media. Most of these researches have been done in an aqueous solution, such as basal medium, deionized water, or Hoagland medium [161]. 


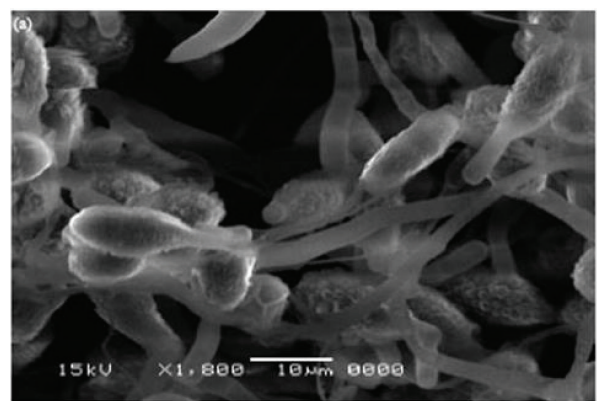

(a)
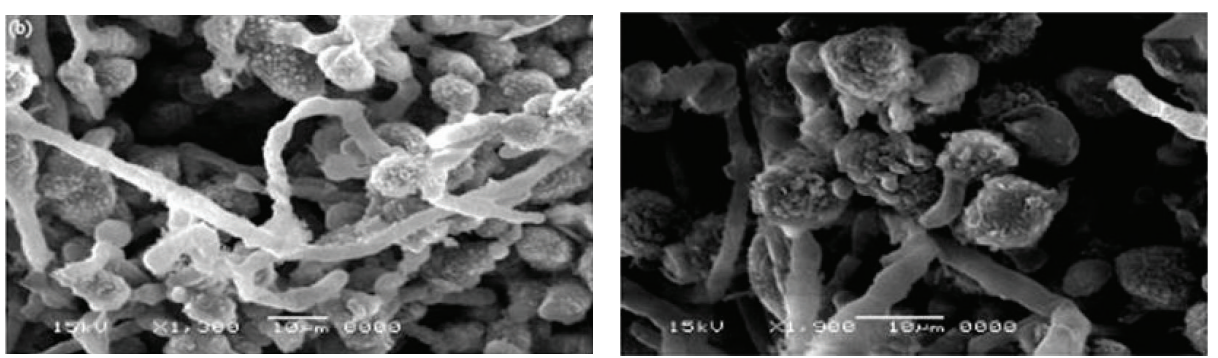

(b)
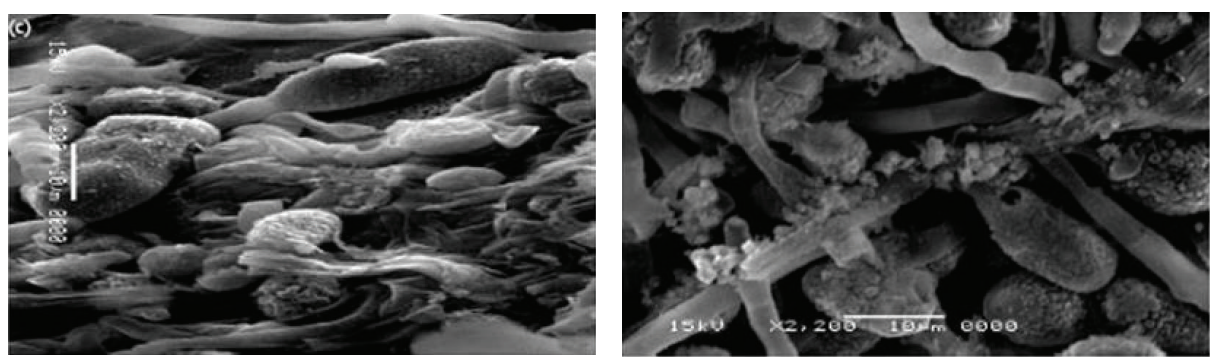

(c)
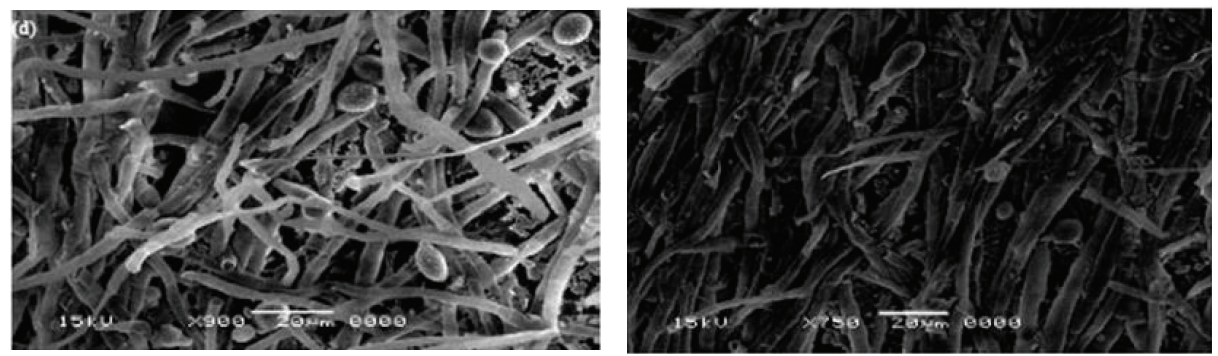

(d)

FIGURE 8: Antifungal effect of Ag nanoparticles on culture filtrate and cell. Scanning electron microscopy images of hyphae of Alternaria alternata treated with silver, copper, or copper/silver nanoparticles. Fungal hyphae grown on potato dextrose agar plates as (a) control or supplemented with $15 \mathrm{mgL}^{-1}$, (b) $\mathrm{Ag}$, (c) $\mathrm{Cu}$, or (d) $\mathrm{Ag} / \mathrm{Cu}$ nanoparticle solution, respectively, Photos were taken at seven days after the incubation period [29].

Few researches documented the toxicity effects of $\mathrm{Ag}$ nanoparticles on seed germination, plant uptake, and translocation of nanoparticles in soil [172-174]. Furthermore, the toxicity and bioavailability of $\mathrm{Ag}$ nanoparticles to species Polyboroides radiatus and Sorghum bicolor were measured in both soil medium and agar [175-177, 179]. Polyboroides radiatus and Sorghum bicolor in agar media displayed Ag nanoparticles' concentration dependent-growth inhibition and the EC50s values of Polyboroides radiatus and Sorghum bicolor calculated to be 13 and $26 \mathrm{mgL}^{-1}$, respectively [178, 180]. Polyboroides radiatus were not affected by the impediment within the test concentration in the soil media. S. bicolor showed a slightly reduced growth rate [178]. Bioavailability and effect of Ag-ions dissolved from Ag nanoparticles are noted to be less in soil than in agar. The results of this research confirmed that bioaccumulation, phytotoxicity, and dissolution of Ag nanoparticles are clearly influenced by the exposure medium [180]. 


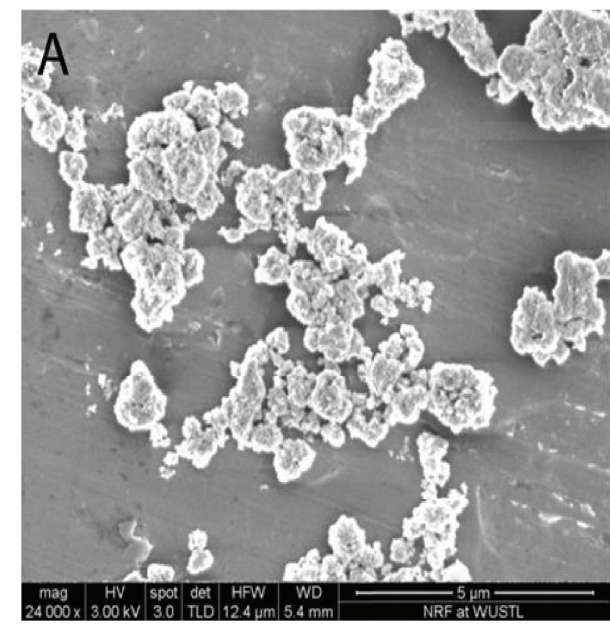

(a)

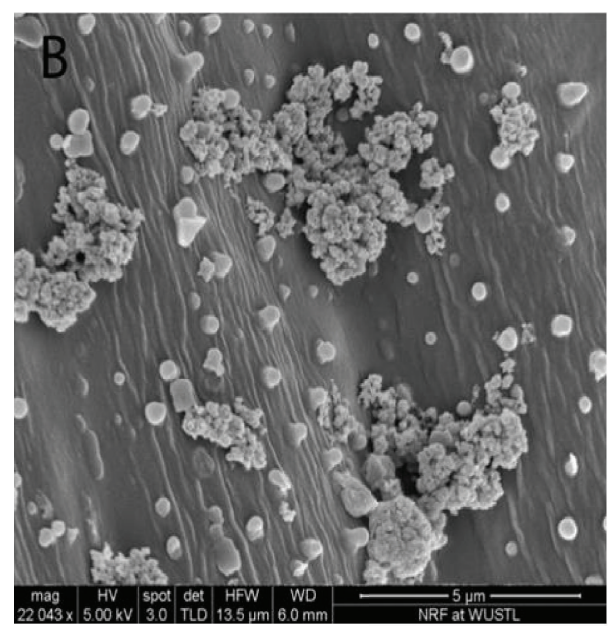

(b)

FIGURE 9: Scanning electron microscope images for NPs/lettuce seeds. In the aqueous phase, the SEM image shows that metal oxide NPs (TiO2 NPs $1000 \mathrm{mgL}^{-1}$ ) (a) and (CuO NPs $1000 \mathrm{mgL}^{-1}$ ) were adsorbed on the seed surface (b) [30].

All such studies throw light on the need for a more genotoxic and cytotoxic evaluation by considering the properties of Ag nanoparticles, uptake, translocation, and distribution in different plant tissues.

3.2.3. Cd: On Plant Growth. The short-term effects of Cadmium (Cd) nanoparticles for the root growth of carrot, cucumber, tomato, and lettuce species were examined, utilizing standard toxicity testing [180-194]. The results indicated that the seedling growths were inversely related to the exposure concentration of $\mathrm{Cd}$, and among the tested plants, the sensitive endpoint appeared in order of tomato, carrot, lettuce, and cucumbers [181-183]. The root growth has not been meaningfully inhibited by the presence of $\mathrm{Cd}$ nanomaterials, except for tomatoes, but remarkably promoted by particular Cd nanomaterials [182]. Microscopic images displayed the roots of tested plants exposed to $\mathrm{Cd}$ showed a reduction in the root wilt and diameter and the disintegration of the root epidermis; the clutter root surface exhibited evident stress in Cd solution [184-186]. After the addition of Cd nanoparticles, many root hairs and a lack of disintegration on the surface soft of the root system were observed, and Cd nanoparticles crystals were also detected on the plants' root surface [187189].

3.2.4. $\mathrm{TiO}_{2}$ : On Plant Growth. Although titanium oxide nanoparticles $\left(\mathrm{TiO}_{2}\right)$ are extensively utilized in daily life products, the research of their uptake and translocation in the plant is restricted, particularly on food crops [195-215]. Due to its small size $(<5 \mathrm{~nm}), \mathrm{TiO}_{2}$ nanoparticles tend to form a covalent bond with most of the no-conjugate natural organic matter, translocate, and following the tissue and cells' specific distribution [198-202]. The overall toxic effects of $\mathrm{TiO}_{2}$ nanoparticles are found in the algal species, such as Desmodesmus subspicatus [216]. Furthermore, $\mathrm{TiO}_{2}$ nanoparticles produce reactive oxygen species upon interaction with organisms or ultraviolet radiation [199-214]. For example, with the presence of $\mathrm{TiO}_{2}$, the root of $A$. thaliana releases mucilage and forms a pectin hydrogel capsule neighboring the root $[205,208]$.

$\mathrm{TiO}_{2}$ nanoparticles show an increase in nitrate reeducates in Soybean (Glycine max), enhance the ability to absorb/use water, and stimulate the antioxidant system. For example, $\mathrm{TiO}_{2}$ nanoparticles treated seeds produced plants that had $73 \%$ more dry weight, three times higher photosynthetic rates, and $45 \%$ rise in chlorophyll a formation compared to the control over the germination period of 30 days [215]. The growth rate of spinach seeds, on the contrary, is proportional to the size of the materials, indicating that the smaller the nanomaterials, the better the germination. Some studies claimed that the $\mathrm{TiO}_{2}$ nanoparticles might have elevated the absorption of inorganic nutrients, accelerated the breakdown of organic substances, and caused quenching by oxygen free radicals formed during the photosynthetic process, consequently improving the photosynthetic rate $[217,218]$. To increase seed germination rate, the key is the penetration of nanomaterials into the seed [30, 219, 220] (Figure 9). Meanwhile, $\mathrm{TiO}_{2}$, in the anatase phase, increases plant growth in spinach by improving nitrogen metabolism that promotes the adsorption of nitrate $[30,218$, 219]. The same study indicated the negative effects of $\mathrm{TiO}_{2}$ nanoparticles towards the seed germination percentage and the number of roots for the species Oryza sativa L. This, in turn, accelerates the conversion of inorganic nitrogen into organic nitrogen, thus increasing the fresh and dry weight [221].

Using bulk and nanosized $\mathrm{TiO}_{2}$ at $60 \mathrm{mgL}^{-1}$ promoted sage and seed germination percentages $[69,200]$. Exposure of sage seeds to $60 \mathrm{mgL}^{-1}$ bulk and $\mathrm{TiO}_{2}$ nanoparticles gained the lowest mean germination time, but higher concentrations did not increase the mean germination time [198, 199]. Application of seeds to $\mathrm{TiO}_{2}$ nanoparticles increased 
the vigor index of sage compared to the control and bulk $\mathrm{TiO}_{2}$ treatments.

For spinach seeds, $\mathrm{TiO}_{2}$ nanoparticles assisted water absorption, and consequently accelerated seed germination $[30,217]$. Thus, some studies declared that altered $\mathrm{TiO}_{2}$ nanoparticles were tested in the liquid phase on the plant model Vicia faba, which was exposed to three nominal concentrations: 50,25 , and $5 \mathrm{mg}$ commercial sunscreen $\mathrm{TiO}_{2}$ nanoparticles per liter for $48 \mathrm{~h}$. Plant growth, photosystem II maximum quantum yield, genotoxicity by micronucleus test, and phytochelatins levels indicated a lack of alteration compared to the control samples. $\mathrm{TiO}_{2}$ nanoparticles seem not to exert deleterious effects on our plant model in $48 \mathrm{~h}$, but the observed important clogging onto the roots [222]. It is shown that a combination of nanosized $\mathrm{TiO}_{2}$ could improve the nitrate reductase enzyme in soybean (Glycine max), increase its abilities of absorbing and utilizing fertilizer and water, encourage its antioxidant system, and actually hasten its germination and growth [223]. In addition, it is stated that the positive effects of $\mathrm{TiO}_{2}$ could be due to antimicrobial properties of ENs, which can improve the strength and resistance of plants to stress.

Therefore, the acute toxic effects of $\mathrm{TiO}_{2}$ nanoparticles are considered low, with the effects not following a clear doseeffect relationship. This is perhaps due to particle agglomeration and subsequent sedimentation. Genomic DNA quantification was detected in the root tips of cucumber after seven days and indicated that plants treated with $2000-4000 \mathrm{mgL}^{-1}$ of $\mathrm{TiO}_{2}$ nanoparticles reduced the genomic DNA compared to the control sample $[205,208]$. The toxic effect of $\mathrm{TiO}_{2}$ nanoparticles is possibly not attributed by the released $\mathrm{Ti}^{2+}$ ions from particles that are tentatively proved by the limited dissolution of $\mathrm{Ti}$ from a $\mathrm{TiO}_{2}$ sample [200].

However, the presence of $\mathrm{TiO}_{2}$ also positively impacts the plants' growth. For example, $\mathrm{TiO}_{2}$ nanoparticles were observed to promote the growth of spinach through an improvement in nitrogen metabolism and photosynthetic rate.

3.2.5. $\mathrm{Al}_{2} \mathrm{O}_{3}$ : On Plant Growth. Phytotoxicity of uncoated and phenanthrene-coated alumina $\left(\mathrm{Al}_{2} \mathrm{O}_{3}\right)$ nanoparticles showed that uncoated $\mathrm{Al}_{2} \mathrm{O}_{3}$ nanoparticles at $2 \mathrm{mgL}^{-1}$ concentrations inhibited the root elongation of cucumber, corn, carrot, cabbage, and soybean [224-226]. It is mentioned that the toxic effect is probably not nanospecified but is due to the dissolution of $\mathrm{Al}_{2} \mathrm{O}_{3}$ nanoparticles. The effects of submicron $\mathrm{Al}_{2} \mathrm{O}_{3}$ particles were investigated to evaluate the chemical material that might be toxic towards the growth of seedling roots [225-228]. Thus, particle surface characteristics play a critical role in the phytotoxicity of $\mathrm{Al}_{2} \mathrm{O}_{3}$ nanoparticles [227].

This supported the fact that the presence of $\mathrm{Al}_{2} \mathrm{O}_{3}$ can stunt root growth in cucumber, corn, carrot, cabbage, and soybean, although preliminary findings suggest extremely high concentrations of such particles are necessary to induce damage [229-231]. The presence of $\mathrm{Al}_{2} \mathrm{O}_{3}$ nanoparticles did not have a negative effect on the growth of Lolium perenne and Phaseolus vulgaris in the tested concentration range $[232,233] . \mathrm{Al}_{2} \mathrm{O}_{3}$ nanoparticles concentration in rye grass improved the control analysis by 2.5 times, with no uptake was observed in kidney beans, which inferred the difference in the uptake and distribution efficiency of different plants by similar nanoparticles [234-239].

3.2.6. $\mathrm{Fe}_{3} \mathrm{O}_{4}$ : On Plant Growth. The excess amount of iron oxide $\left(\mathrm{Fe}_{3} \mathrm{O}_{4}\right)$ as a magnetic nanomaterial resulted in some negative effect towards plant growth. For example, "Chlorophyll a" levels were amplified at low $\mathrm{Fe}_{3} \mathrm{O}_{4}$ nanoparticles fluid concentrations, while at higher concentrations it inhibited it [240-242]. A small inhibitory effect was discovered on the growth of the plantlets that led to brown spots on leaves at higher volume fractions of $\mathrm{Fe}_{3} \mathrm{O}_{4}$ nanoparticles fluids [243245]. The excess $\mathrm{Fe}_{3} \mathrm{O}_{4}$ nanoparticles treatment produced some oxidative stress, which in turn affected photosynthesis and resulted in decreased rates of metabolic process [246248]. The oxidative stress was induced by the $\mathrm{Fe}_{3} \mathrm{O}_{4}$ fluid concentration in the tissues of living plants [245-247].

In order to overcome such limitations, the coating provides $\mathrm{Fe}_{3} \mathrm{O}_{4}$ nanoparticles with a large adsorption surface and biocompatible properties [249-252]. For example, in the case of pumpkin (Cucurbita pepo), the presence of carbon coated- $\mathrm{Fe}_{3} \mathrm{O}_{4}$ at certain concentrations within some cells and in extracellular space decreases the problems for plant tissues and the amount of chemicals released into the environment [250]. Furthermore, the influence of tetramethylammonium hydroxide coated $\mathrm{Fe}_{3} \mathrm{O}_{4}$ nanoparticles on the growth of corn (maize) found that the chlorophyll level increased at low $\mathrm{Fe}_{3} \mathrm{O}_{4}$ nanoparticle fluid, while at higher concentrations it was inhibited [253].

A slight inhibitory effect was observed in the growth of the plantlets, which in turn resulted in brown spots on leaves at greater volume fractions of the magnetic fluid [254, 255]. The oxidative stress was induced by the $\mathrm{Fe}_{3} \mathrm{O}_{4}$ nanoparticles fluid towards the living plant tissue [256-258]. The excess $\mathrm{Fe}_{3} \mathrm{O}_{4}$ nanoparticles generated some oxidative stress, affected photosynthesis, and resulted in the reduction of metabolic process rates.

3.2.7. $\mathrm{Zn} / \mathrm{ZnO}$ : On Plant Growth. Zinc ( $\mathrm{Zn})$ and zinc oxide $(\mathrm{ZnO})$ are categorized as commonly used metal/metal oxide engineered nanomaterials. $\mathrm{Zn}$ is an essential micronutrient for humans, animals, and plants [259-263]. ZnO is mostly utilized in a range of applications such as sunscreens and other personal care products, solar cells, and photocatalysis, biosensors, and electrodes [261]. According to the analysis of 289 soil samples collected from different countries in the world, $\mathrm{Zn} / \mathrm{ZnO}$ deficiency was found to be the most widespread micronutrient deficiency and the fourth most important yield-limiting nutrient after nitrogen, phosphorus, and potassium [260-262].

Due to its increasing utilization in consumer products, it is quite possible that through both accidental release and deliberate application, $\mathrm{Zn} / \mathrm{ZnO}$ might find their way into atmospheric environments, whether terrestrial or aquatic [263-266]. It induces noticeable effect on many organisms, especially on plants, which are an essential base component to all ecosystems [267]. 
A number of researchers described the key role of $\mathrm{Zn} / \mathrm{ZnO}$ nanomaterials for plant growths and yield [265267]. For example, higher plant mostly absorbs $\mathrm{Zn}$ as a divalent cation $\left(\mathrm{Zn}^{2+}\right)$, which acts either as a functional, structural, or as the metal component of enzymes or a regulatory cofactor of numerous enzymes [266]. Zn nanomaterials are needed for chlorophyll production, fertilization, pollen function, and germination. Among the micronutrients, $\mathrm{Zn}$ affects the susceptibility of plants via drought stress [263]. The germination rate of the plant may be affected in the presence of $\mathrm{Zn}$ and $\mathrm{ZnO}$. $\mathrm{ZnO}$ nanomaterials are hazardous and affect both the chromosomal and the cellular facets. Clear root germination effects, due to the presence of $\mathrm{ZnO}$, were observed for the species of Buckwheat (Fagopyrum esculentum) [31] (Figures 10 and 11). Furthermore, the presence of the $\mathrm{ZnO}$ nanoparticles also promoted the permeation of onion (Allium сера) roots and effected the roots' elongation, genetic materials, and metabolisms. The $\mathrm{ZnO}$ suspension meaningfully inhibited root growth of corn, with the termination of root development.

Growth of roots was halted with seed soaking and incubation in the suspension of $\mathrm{Zn} / \mathrm{ZnO}$ nanoparticles. It also indicates that $\mathrm{Zn}^{2+}$ is more toxic in ryegrass species compared to $\mathrm{ZnO}$ nanoparticles [31, 258-268]. The root growths are found in seedling of ryegrass, radish, and rape exposed to less than $10 \mathrm{mgL}^{-1}$ of $\mathrm{ZnO} / \mathrm{Zn}$ nanoparticles. The toxicity of $\mathrm{ZnO}$ nanoparticle could not mostly come from its dissolution at the root surface, but also inside the tissue [31].

The toxicity of $\mathrm{ZnO}$ nanoparticle and $\mathrm{Zn}^{2+}$ could be derived by two theories; a chemical toxicity based on chemical composition and the stress or stimuli caused by the size, shape, and surface of the $\mathrm{ZnO}$ nanoparticles [266]. Both theories significantly affected the cell culture response of the plants. A number of mechanisms underlined the efficiency of $\mathrm{Zn} / \mathrm{ZnO}$. Depending on the plant species and the experimental conditions, the most important mechanism may be $\mathrm{Zn} / \mathrm{ZnO}$ utilization in tissues, called the internal efficiency, or $\mathrm{Zn} / \mathrm{Zn}$ uptake, called the external efficiency [267]. This, in turn, helped $\mathrm{ZnO}$ nanoparticle enter the root cells and inhibit seedling growth.

3.2.8. $\mathrm{Cu} / \mathrm{Cu}_{2} \mathrm{O}$ : On Plant Growth. Copper/Copper oxide $\left(\mathrm{Cu} / \mathrm{Cu}_{2} \mathrm{O}\right)$ nanoparticles could block water channels through adsorption and increase the possibility for radical penetration into onion roots [269-271]. This, in turn, spoils the complete stages of cell division and cellular metabolism [270]. The bioavailability and toxicity of $\mathrm{Cu}$ nanoparticles to the Mung bean (Phaseolus radiates) and wheat (Triticum aestivum) species employed plant agar test as a growth substrate for the homogenous exposure of nanoparticles. The rate of growth for both species were inhibited; as a result of exposure to $\mathrm{Cu}$, nanoparticles and the seedling length of tested species are inversely related to the exposure concentration of $\mathrm{Cu}$ nanoparticles.

The toxicity and bioavailability of $\mathrm{Cu}$ nanoparticles were observed on the plants Mung bean (Phaseolus radiates) and wheat (Triticum aestivum). The observation employed plant agar test as the growth substrate for the homogeneous exposure of nanoparticles [272-274]. The growth rates of both plants were inhibited, and due to the exposure to nanoparticles and the seedlings, the lengths of the tested species were inversely related to the exposure concentration of the nanoparticles [273]. Wheat crop showed a greater accumulation of $\mathrm{Cu}$ nanoparticles in its roots due to the roots' morphology. The bioavailability was estimated by calculating the bioaccumulation factor defined as the $\mathrm{Cu}$ nanoparticles concentration in the plants, divided by the concentration of $\mathrm{Cu}$ nanomaterials in the growth media [275]. Growth inhibition of a seedling exposed to different concentrations of $\mathrm{Cu}$ nanomaterials on Mung bean (Phaseolus radiates) was more sensitive compared to wheat (Triticum aestivum) [276]. A cupric ion released from $\mathrm{Cu}$ nanoparticles had negligible effects on the concentration ranges of the present study, and the apparent toxicity was clearly the result of $\mathrm{Cu}$ nanomaterials $[277,278]$.

With increasing concentration of $\mathrm{Cu}$ nanoparticles and agglomeration of particles, the rates of bioaccumulation increased. Bioaccumulation of $\mathrm{Cu}$ nanoparticles increased with its concentration in the growth media, and their bioavailability to the test plants was estimated by calculating the bioaccumulation factor. Some studies demonstrated the plant agar test as a good protocol to test phytotoxicity of $\mathrm{Cu}$ nanoparticles, which is hardly water-soluble [279]. Moreover, studies on the effects of $\mathrm{Cu}$ nanoparticles on the growth of zucchini plants showed the reduced length of emerging roots [275], although the germination of lettuce seeds in the presence of $\mathrm{Cu}$ nanomaterials showed an increase in the shoot-to-root ratio compared to the control plants [280].

Bioavailability was estimated by calculating the bioaccumulation factor defined as the $\mathrm{Cu}$ nanoparticles concentration in the plants divided in the growth media by its concentration. Growth inhibition of a seedling exposed to different concentration of $\mathrm{Cu}$ nanomaterials on Mung bean (Phaseolus radiates) was more sensitive than wheat (Triticum aestivum). $\mathrm{Cu}^{2+}$ ions released from $\mathrm{Cu}$ nanomaterials had negligible effects on the concentration ranges and the apparent toxicity clearly resulting from $\mathrm{Cu}$ nanoparticles [276]. Thus, bioaccumulation increased with the concentration of $\mathrm{Cu}$ nanoparticles and the agglomeration of the particles [281]. The increments on bioaccumulation were derived from growth media and its bioavailability to the tested plant was estimated by calculating the bioaccumulation factors. Studies on the effect of $\mathrm{Cu}$ nanoparticles on the growth of zucchini plants indicated a reduction in the length of emerging roots [282]. However, the germination of lettuce seeds in the presence of $\mathrm{Cu}$ nanomaterials showed an increment in the shoot-to-root ratio compared to the control plant. The effect of $\mathrm{Cu}$ nanoparticles' toxicity to the plant and food crops is evident, with the clear impacts on crop growth, root length, shoot length, biomass accumulation, and germination visualized from the contaminated plants [281].

3.2.9. $\mathrm{Ce} / \mathrm{CeO}_{2}$ : On Plant Growth. Cerium oxide $\left(\mathrm{CeO}_{2}\right)$ nanoparticles utilized in several emerging applications which leverage the UV absorbing capacity and high $\mathrm{O}_{2}$ storage of $\mathrm{CeO}_{2}$ nanoparticle and the low redox potential of the $\mathrm{Ce}$ 

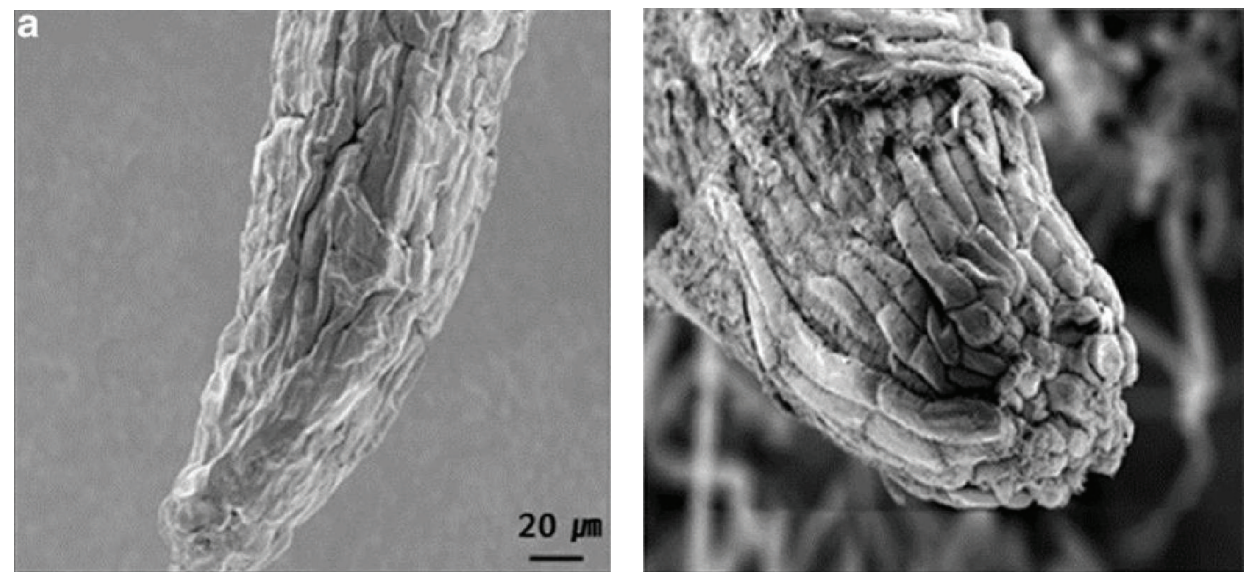

(a)
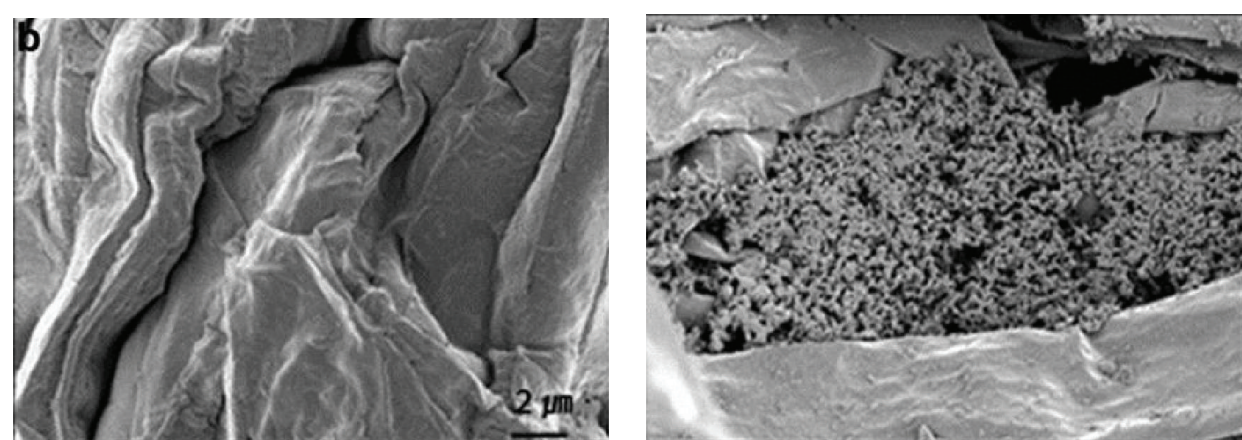

(b)
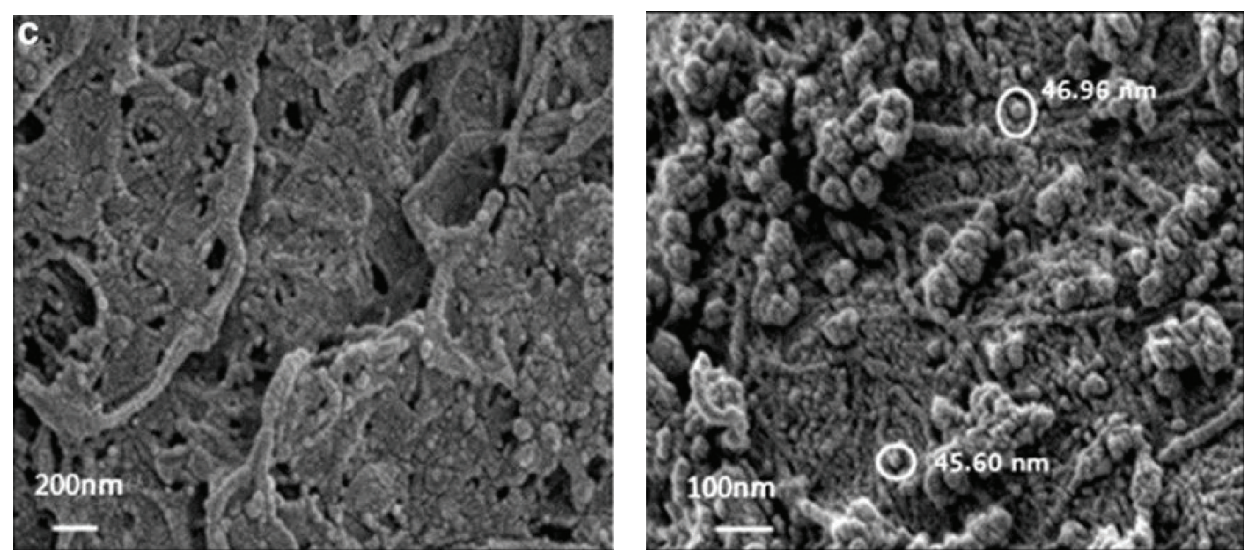

(c)

FIGURE 10: Scanning electron microscope images of Buckwheat (Fagopyrum esculentum) root surface under control (left) and treatment (right) with $\mathrm{ZnO}$ nanoparticles $\left(1,000 \mathrm{mgL}^{-1}\right)$ at a magnification of $\times 1,000(\mathrm{a}), \times 5,000$ (b), and $\times 150,000$ (c) [31].

IV/Ce III redox couple [35]. The natural environment may expose to $\mathrm{CeO}_{2}$ nanoparticle from exhaust catalysts after deposition on plant, when they are collected with road runoff, or by industrial wastewaters that contain $\mathrm{CeO}_{2}$ nanoparticles. Very fine $(<1 \mu \mathrm{m})$ exhaust particulates cause very diffuse pollution, and $\mathrm{CeO}_{2}$ nanoparticles contamination does not cause a noteworthy cerium (Ce) enrichment in natural waters. Besides, $\mathrm{CeO}_{2}$ nanoparticles, as the only tetravalent metal oxide, showed very different effects on the test plant species [35].
Possible toxicity, transport, fate and of $\mathrm{CeO}_{2}$ nanoparticles remain unknown. Some works have focused on effect of $\mathrm{CeO}_{2}$ (concentration at 0 to $4000 \mathrm{mgL}^{-1}$ ) on seeds of tomato (Lycopersicon esculentum), cucumber (Cucumis sativus), alfalfa (Medicago sativa), and corn (Zea mays). The results found that $\mathrm{CeO}_{2}$ nanoparticles meaningfully decreased corn germination (about $30 \%$ at $2000 \mathrm{mgL}^{-1}$; $P<0.05$ ), and at $2000 \mathrm{mgL}^{-1}$, the germination of tomato and cucumber was reduced by 30 and $20 \%$, respectively $(P<0.05)$ [283]. The root growth significantly promoted 


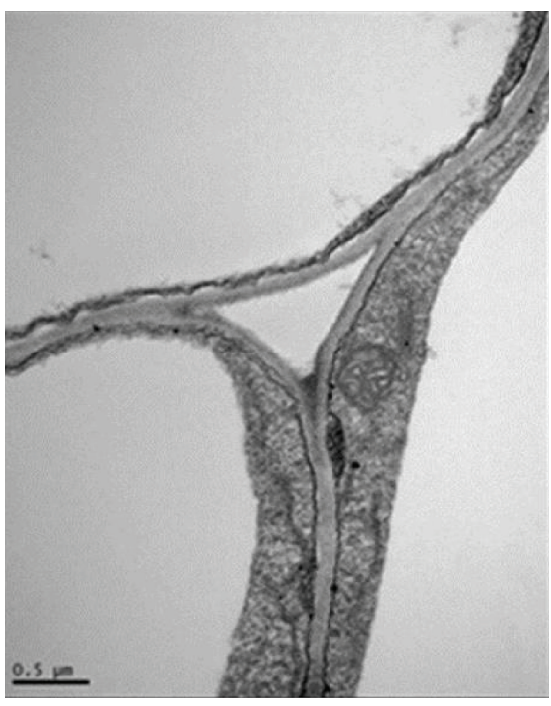

(a)

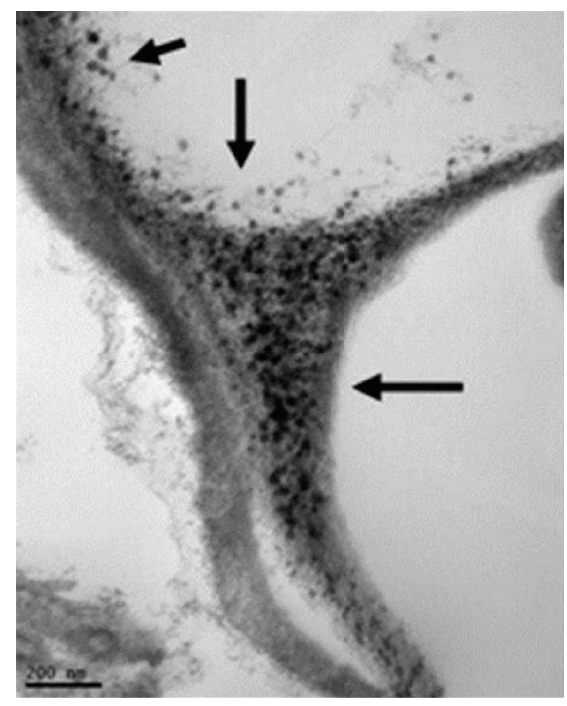

(b)

FIGURE 11: Transmission electron microscopy images of Buckwheat (Fagopyrum esculentum) root surface under control (a) and treatment (b) with $\mathrm{ZnO}$ nanoparticles $\left(1,000 \mathrm{mgL}^{-1}\right)$ [31].

$(P<0.05)$ by $\mathrm{CeO}_{2}$ nanoparticle in cucumber and corn but reduced $(P<0.05)$ in alfalfa and tomato. However, a suspension of $2000 \mathrm{mgL}^{-1} \mathrm{CeO}_{2}$ nanoparticle had no effect on the root elongation of radish, rape, tomato, wheat, cabbage, and cucumber, except lettuce [257].

Furthermore, few reports consequently far have addressed the entire life cycle of plants grown in ENscontaminated soil. Soybean (Glycine max) seeds germinated and grown to full maturity in organic farm soil amended with either $\mathrm{ZnO} \mathrm{ENs}$ at $500 \mathrm{mg} / \mathrm{kg}$ or $\mathrm{CeO}_{2} \mathrm{ENs}$ at $1000 \mathrm{mg} / \mathrm{kg}$. In other study, the short-term effects of $\mathrm{CeO}_{2}$ nanoparticle in two different agglomeration states on the green algae Chlamydomonas reinhardtii were examined. It demonstrated that the level of dissolved cerium (III) in $\mathrm{CeO}_{2}$ ENs suspensions was very low and between 0.1 and $27 \mathrm{nM}$ [284]. The agglomerated $\mathrm{CeO}_{2}$ ENs caused a slight decrease of photosynthetic yield at the highest concentrations (100 M), while no effect observed for dispersed $\mathrm{CeO}_{2}$ ENs. The low toxicity of agglomerated $\mathrm{CeO}_{2}$ ENs was attributed quantitatively to $\mathrm{Ce}^{3+}$ ions cooccurring in the nanoparticle suspension whereas for dispersed $\mathrm{CeO}_{2}$ ENs, dissolved $\mathrm{Ce}^{3+}$ precipitated with phosphate and not bioavailable [257, 283].

\section{Engineered Nanomaterials: Interaction and Mechanism in Plant}

Interaction of ENs and plants can be categorized under phytotoxicity, uptake, translocation, and accumulation. Current literature revealed that all of the aforementioned interactions depend on the species of the plant, its type, size, chemical composition, stability, and functionalization of ENs.

4.1. Engineered Nanomaterials: Phytotoxicity Mechanism. Phytotoxicity studies using higher plants are an important criterion for understanding the toxicity of ENs. The vast majority of research dedicated to the potential toxicity of ENs to plants and both negative and positive or inconsequential effects have been reported $[48,52,97]$. The majority of the reports available in the literature indicate the phytotoxicity of ENs [94, 104]. For example, a pronounced increase in the rate of germination was observed for rice seeds in the presence of some of carbon nanomaterials, particularly CNTs [101-103]. Increased water content observed in the CNT-treated seeds during germination was compared to the control samples. The germinated seeds grown in a basal growth medium were supplemented with CNTs in order to study their impact on further seedling growth [102]. The results indicate possible use for CNTs as enhancers in the growth of rice seedlings. Another example derived from $\mathrm{Al}_{2} \mathrm{O}_{3}$ nanomaterials inhibit root elongation of cucumber, corn, soybeans, carrot, and cabbage [225-228], while $\mathrm{ZnO}$ nanomaterials were reported to be one of the most toxic nanomaterials that could terminate root growth of test plants [260-262]. Similar studies were carried out on the toxicology of $\mathrm{Al}_{2} \mathrm{O}_{3}, \mathrm{SiO}_{2}, \mathrm{ZnO}$, and $\mathrm{Fe}_{3} \mathrm{O}_{4}$ on Arabidopsis thaliana, with the results showing that $\mathrm{ZnO}$ nanomaterials at $400 \mathrm{mgL}^{-1}$ capable of inhibiting germination [265-267]. From a toxicological perspective, surface area and particle size are important material characteristics. As the size of the particles decreases, its surface area increases, and allows a greater proportion of its atoms or molecules to be displayed on the surface rather than the interior of the ENs $[28,117]$. The increase of surface area determines the potential number of reactive groups on the particles' surface [117]. The change in the structural and physicochemical properties of ENs, with a decrease in size, could be responsible for a number of material interactions that could result in toxicological effects [178]. One of the earliest observations on the effect of surface properties on toxicity of ENs showed greater toxicity than 
fine particulate of similar materials on the basis of mass $[182,183]$. This has been observed with different kinds of ENs, including $\mathrm{TiO}_{2}$, carbon black, $\mathrm{Co}$, and $\mathrm{Ni}$. It was found that $\mathrm{TiO}_{2}$ nanoparticle with a size of $21 \mathrm{~nm}$ resulted in 43 times more inflammation than $250 \mathrm{~nm}$ particles based on similar mass [198-202]. The increase in inflammation is believed to be caused by much greater surface area of the small particles for similar masses of material. Another example derived from the applicability of fluorescein isothiocyanate labeled silica nanoparticles and photo-stable Cadmium-Selenide quantum dots were tested for their ability to be used as biolabels, and for promoting seed germination [285-287]. It was found that FTIC-labeled silica nanoparticles induced seed germination in rice, while quantum dots arrested the germination. Multiple studies showed that nanosized particles are more toxic than microsized particles [286]. Intrinsic surface reactivity is another factor that determined the toxicity of ENs. It was determined that other types of crystalline anatase $\mathrm{TiO}_{2}$ did not show size intensive toxicity for nanosized particles $[30,219,220]$. Overall, the current phytotoxicity profile of ENs is highly speculative and preliminary, and the effects of their unique characteristics are poorly understood and more studies on toxicity are required, especially on commercial food crop [185].

Toxic effect of ENs brought from the dissolved species that originated from dissolution, which in turn could increase the damage to genetic materials, agglomeration, and biomass production, while reducing the length of the roots $[117,183]$. However, there are still positive effects on the accumulation of nanomaterials in plants, especially in multiwall carbon nanotube, $\mathrm{Zn}$, and $\mathrm{ZnO}$ [265-267]. The presence of these nanomaterials induces the germination and seedling growth of Brassica Juncea and black gram (Phaseolus Mungo) [94]. The toxicity of various organisms depends on the nature of particles, sizes, concentration, and exposure times [186, 187]. The theory on the extension effect remains unclear, from nanoformulation, fraction, or size of the nanomaterials $[193,199]$. Nevertheless, some studies have indicated that the phytoxicity observed on the exposure to $\mathrm{ZnO}$ nanoparticles may be attributed solely to dissolved-Zn, which was similar to the conclusion drawn regarding $\mathrm{Au}$ nanoparticles [259]. Another study discovered that the toxic effect by $\mathrm{ZnO}$ is more significant in seed germinations, root elongations, and the number of leaves, rather than other nanoparticles [263]. Furthermore, studies on the relevance of phytotoxicity on rice (Oryza sativa) towards Au nanoparticles have been analyzed and from the micrograph analysis found that various particle sizes deposited inside the root cells through the small pores of cell walls are done via cellular mechanism [136-138].

In conclusion, most of the studies demonstrated direct exposure to specific types of nanoparticles causing significant phytotoxicity, emphasizing the need for ecologically responsible disposal of wastes containing ENs. It also highlights the necessity for further study on the impacts of ENs on agricultural and environment systems.

4.2. Engineered Nanomaterials: Uptake Mechanism. One of the major research gaps on the uptake mechanism of nanomaterials towards plants is the absence of consistent and broadly applicable information [65, 278]. Most information revealed that ENs could adhere to plant roots and exert chemical or physical uptakes upon plants [245, 273]. Recently, there are an increasing number of publications emerging on the interaction of ENs with plants [241]. The uptake, accumulation, and build-up of nanoparticles vary, and these factors largely depend on the type, size, and the composition of the plant. Indeed, the verification on the uptake mechanism of ENs is limited and is focused on stock solutions rather than the actual concentration [102, 139]. The stock solution is prepared either from a series of dilution or media renewable periods. As such, most method being reported might not produce similar results for different shapes, sizes, and forms of nanomaterials [187]. Most of the data correspond to the germination stage and cell culture, which are mostly focused on metal-based nanomaterials, such as $\mathrm{TiO}_{2}, \mathrm{CeO}_{2}, \mathrm{Fe}_{3} \mathrm{O}_{4}, \mathrm{ZnO}, \mathrm{Au}, \mathrm{Ag}, \mathrm{Cu}$, and Fe. In this case, only fullerene and fullerols showed a ready uptake in plants.

Several avenues for the uptake of nanomaterials by plant cells are proposed. Some of the data suggested that the nanomaterials could enter plant cells by being bound to a carrier protein, through aquaporin, ion channels, or endocytosis via the creation of new pores, ending up being bounded to organic chemicals [191, 205]. This phenomenon is preferred in the case of carbon nanotubes rather than other types of nanomaterials [102]. Meanwhile, the greater surface area-tomass ratio of the nanoparticle compared to the bulk metals induces higher reactivities compared to the surroundings [213]. Consequently, the nanomaterials may form complexes with membrane transporters or root exudates before being transported into the plants. Most metal-based nanomaterials that have been reported as being taken up by plants include elements for which ion transporters have been identified [278]. Once the nanomaterials enter the plant cells, it may be transported either apoplastically or symplastically from one cell to another via plasmodesmata [139].

However, the relations between the selectivity of the uptake of nanomaterial and the type of plant remain unknown and are open to exploration. Some studies suggested that the gradual increase in ENs uptake was observed with reducing granule size, and only the powder from produced plants with ENs concentrations remains in the sufficient range [213, 273]. For example, $\mathrm{ZnO}$ granule of $1.5 \mathrm{~mm}$ weigh less than granules of 2.0 or $2.5 \mathrm{~mm}$, smaller granules utilized for similar weights, resulting in a better distribution of $\mathrm{Zn}$ and the higher surface contact area $\mathrm{Zn}$ fertilizer, resulting in better $\mathrm{Zn}$ uptake [266]. Ample work was done, emphasizing the role of particle size in increasing the efficiency of ENs uptake and higher yields.

\subsection{Engineered Nanomaterials: Translocation Mechanism.} Prior to translocation, engineered nanomaterials are intermediate in its mobility or phloem export. Some studies suggested that the translocation of ENs depends on the amount being supplied and the nature of the plant as a species [11]. Engineered nanomaterials move from leaves to roots, stem, and developing grain, and from one root to another. 
The higher translocation of other nutrient is recorded by the increment on its demand [240]. The translocation mechanism is initiated with the penetration of ENs through cell walls and plasma membrane of root cells. One of the main passages of uptake and transportations to the shoot and leave(s) of plant is the Xylem [288, 289]. In this case, the pore size of cell wall must be in range of $3-8 \mathrm{~nm}$, which is smaller than ENs. The penetration rate was studied with leek (Allium porrum), and it was found that ENs pathway in the leaf was followed with the stomatal pathway [289].

\subsection{Engineered Nanomaterials: Transmission Mechanism.} The first step to understand the possible benefits of applying nanotechnology to agriculture should be to analyze the transmission mechanism of ENs in plants. Transmission of ENs was detected at different levels: chains of nanomaterialsaggregates carrying cells apparently close to the application point, when such application was made by the "injection" of the ENs suspension into the pith cavity of the stem, suggesting the presence of flux of nanoparticles from one cell to another [290]. The nanomaterials are capable of penetrating through the leaf cuticle and into the cell cytoplasm [291, 292]. Plants provide a potential pathway for the transport of nanomaterials to the environment and serve as an important route for their bioaccumulation into the food chain [292]. The wall of the plant's cell acts as a barrier for easy entry to any external agents, including ENs into plant cells. The sieving properties are determined by the pore diameter of the cell wall, ranging from 5 to $20 \mathrm{~nm}$ [290]. Only ENs aggregates with diameters less than the pore diameter of the cell wall could easily pass through and reach the plasma membrane [291].

There is also a chance for the enlargement of pores or induction of new cell wall pores upon interaction with ENs, which will in turn enhance nanoparticle transmissions [293]. They may also cross the membrane using embedded transport carrier proteins or through ion channels. In the cytoplasm, the ENs may bind with different cytoplasmic organelles and interfere with the metabolic processes at that site [291].

When ENs is applied on the surface of leaves, they will enter through the stomata openings or through the bases of trichomes and then translocated to various tissues. However, the accumulation of ENs on photosynthetic surface causes foliar heating, which results in the alterations to gas exchange, due to stomata obstruction that produces changes in various physiological and cellular functions of plants. The application of microscopy techniques visualizes and tracks the transport and deposition of ENs inside the plants [294]. The ENs tagged to agrochemicals or to other substances could reduce the injury to plant tissues and the amount of chemicals released into the environment; a certain contact is however unavoidable, due to the strong interaction of plants with soil growth substrates [295].

This limitation is circumvented by coating. For example, the carbon-coated $\mathrm{Fe}_{3} \mathrm{O}_{4}$ nanomaterials (carbon encapsulation provides biocompatibility and a large adsorption surface) in living plants such as pumpkins (Cucurbita pepo) and the results showed the presence of nanomaterials both in the extracellular space and within some cells [245].
One of the pathways also reported particle size of $20 \mathrm{~nm}$ Ag nanoparticles may be transported inside the cells through plasmodesmata [169-171]. Particles must enter through the cell wall and the plasma membrane of root cells. Xylem is one of the main passages of uptake and transportations to the shoot and the leaves of plant. Pore size of cell wall was in the range of $3-8 \mathrm{~nm}$, which is smaller than ENs. The penetration rates of foliar applied to polar solutes are highly variable and the mechanism is not fully understood [294]. Investigation in leek (Allium porrum) and broad bean (Vicia faba) size exclusion limits and lateral heterogeneity of the stomata foliar uptake pathway for aqueous solutes and water-suspended nanoparticles were done in [148, 176, 177]. Thus, the nanomaterials pathway in leaf follows the stomata pathway, which differs fundamentally from the cuticolar foliar uptake pathway [269]. This consequently proved the limitation of transmission and the distribution of Ag nanoparticles in Medicago sativa and Brassica juncea. In contrast to Brassica juncea, Medicago sativa showed an increase in metal uptakes with a corresponding increase in the substrate of metal concentration and exposure time [146]. The Ag nanoparticles were located in the nucleus and applied the definition that suggested both Brassica juncea and Medicago sativa hyperaccumulators of Ag nanoparticles.

\section{Conclusion and Prospective}

This work proves that certain engineered nanomaterials could exert chemical or physical toxicity on plants depending on its size, chemical composition, surface energy, and species, leading to different techniques. Hence, the challenges for further research is the uptake kinetics and the interaction mechanism within cells, and also the maximum agreeable amount of these engineered nanomaterials that plants can take without showing any signs of stress. An extensive research on the toxic effects of nanomaterials could meaningfully help by utilizing and disposing engineered nanomaterials for the reduction of adverse effects in both of agricultural and of environmental systems.

\section{Conflict of Interests}

The authors declare that there is no conflict of interests regarding the publication of this paper.

\section{Acknowledgments}

This work is financially supported by University Malaya Research Grant (UMRG RP022-2012E) and Fundamental Research Grant Scheme (FRGS: FP049-2013B) by Universiti Malaya and Ministry of High Education, Malaysia, respectively.

\section{References}

[1] G. C. Delgado-Ramos, "Nanotechnology in Mexico: global trends and national implications for policy and regulatory issues," Technology in Society, vol. 37, no. 1, pp. 4-15, 2014. 
[2] J. Safari and Z. Zarnegar, "Advanced drug delivery systems: nanotechnology of health design A review," Journal of Saudi Chemical Society, vol. 18, no. 2, pp. 85-99, 2014.

[3] O. P. Vilela Neto, "Intelligent computational nanotechnology: the role of computational intelligence in the development of nanoscience and nanotechnology," Journal of Computational and Theoretical Nanoscience, vol. 11, no. 4, pp. 928-944, 2014.

[4] V. Dutschk, T. Karapantsios, L. Liggieri, N. McMillan, R. Miller, and V. M. Starov, "Smart and green interfaces: from single bubbles/drops to industrial environmental and biomedical applications," Advances in Colloid and Interface Science, vol. 209, pp. 109-126, 2014.

[5] A. M. Al-Halafi, "Nanocarriers of nanotechnology in retinal diseases," Saudi Journal of Ophthalmology, 2014.

[6] M. Safiuddin, M. Gonzalez, J. W. Cao, and S. L. Tighe, "Stateof-the-art report on use of nano-materials in concrete," International Journal of Pavement Engineering, 2014.

[7] X. Zhou, M. Torabi, J. Lu, R. Shen, and K. Zhang, "Nanostructured energetic composites: synthesis, ignition/combustion modeling, and applications," ACS Applied Materials and Interfaces, vol. 6, no. 5, pp. 3058-3074, 2014.

[8] R. H. Baughman, A. A. Zakhidov, and W. A. de Heer, "Carbon nanotubes-the route toward applications," Science, vol. 297, no. 5582, pp. 787-792, 2002.

[9] X. Lang, A. Hirata, T. Fujita, and M. Chen, "Nanoporous metal/oxide hybrid electrodes for electrochemical supercapacitors," Nature Nanotechnology, vol. 6, no. 4, pp. 232-236, 2011.

[10] L. Rizzello and P. P. Pompa, "Nanosilver-based antibacterial drugs and devices: mechanisms, methodological drawbacks, and guidelines," Chemical Society Reviews, vol. 43, no. 5, pp. 1501-1518, 2014.

[11] K. Yang and Y. Ma, "Computer simulation of the translocation of nanoparticles with different shapes across a lipid bilayer," Nature Nanotechnology, vol. 5, no. 8, pp. 579-583, 2010.

[12] M. Diao and M. Yao, "Use of zero-valent iron nanoparticles in inactivating microbes," Water Research, vol. 43, no. 20, pp. 52435251, 2009.

[13] J. Y. Ljubimova and E. Holler, "Biocompatible nanopolymers: the next generation of breast cancer treatment?" Nanomedicine, vol. 7, no. 10, pp. 1467-1470, 2012.

[14] D. Astruc, "Electron-transfer processes in dendrimers and their implication in biology, catalysis, sensing and nanotechnology," Nature Chemistry, vol. 4, no. 4, pp. 255-267, 2012.

[15] P. Podsiadlo, A. K. Kaushik, E. M. Arruda et al., "Ultrastrong and stiff layered polymer nanocomposites," Science, vol. 318, no. 5847, pp. 80-83, 2007.

[16] Y. Vasquez, A. E. Henkes, J. Chris Bauer, and R. E. Schaak, "Nanocrystal conversion chemistry: a unified and materialsgeneral strategy for the template-based synthesis of nanocrystalline solids," Journal of Solid State Chemistry, vol. 181, no. 7, pp. 1509-1523, 2008.

[17] R. J. Mehta, Y. Zhang, C. Karthik et al., "A new class of doped nanobulk high-figure-of-merit thermoelectrics by scalable bottom-up assembly," Nature Materials, vol. 11, no. 3, pp. 233-240, 2012.

[18] N. A. Malvadkar, M. J. Hancock, K. Sekeroglu, W. J. Dressick, and M. C. Demirel, "An engineered anisotropic nanofilm with unidirectional wetting properties," Nature Materials, vol. 9, no. 12, pp. 1023-1028, 2010.

[19] L. Kong, J. Tang, J. Liu, Y. Wang, L. Wang, and F. Cong, "Fluorescent nanoblocks of lanthanide complexes on nano silicon dioxide and carbon nanotube donors with ligand-antenna integration (ALI) structure," Materials Science and Engineering C, vol. 29, no. 1, pp. 85-91, 2009.

[20] C. Richard, F. Balavoine, P. Schultz, T. W. Ebbesen, and C. Mioskowski, "Supramolecutar self-assembly of lipid derivatives on carbon nanotubes," Science, vol. 300, no. 5620, pp. 775-778, 2003.

[21] C. Lam, J. T. James, R. McCluskey, and R. L. Hunter, "Pulmonary toxicity of single-wall carbon nanotubes in mice 7 and 90 days after intractracheal instillation," Toxicological Sciences, vol. 77, no. 1, pp. 126-134, 2004.

[22] H. Qi and T. Hegmann, "Impact of nanoscale particles and carbon nanotubes on current and future generations of liquid crystal displays," Journal of Materials Chemistry, vol. 18, no. 28, pp. 3288-3294, 2008.

[23] L. Jinquan, L. Li, C. Hanqing et al., "Application of vitamin E to antagonize SWCNTs-induced exacerbation of allergic asthma," Scientific Reports, vol. 4, article 4275, 2013.

[24] D. B. Warheit, B. R. Laurence, K. L. Reed, D. H. Roach, G. A. M. Reynolds, and T. R. Webb, "Comparative pulmonary toxicity assessment of single-wall carbon nanotubes in rats," Toxicological Sciences, vol. 77, no. 1, pp. 117-125, 2004.

[25] H. W. Zhu, C. L. Xu, D. H. Wu, B. Q. Wei, R. Vajtai, and P. M. Ajayan, "Direct synthesis of long single-walled carbon nanotube strands," Science, vol. 296, no. 5569, pp. 884-886, 2002.

[26] Y. Wu, J. S. Hudson, Q. Lu et al., "Coating single-walled carbon nanotubes with phospholipids," Journal of Physical Chemistry B, vol. 110, no. 6, pp. 2475-2478, 2006.

[27] W. Hou, D. Long, and Y. Wu, “The homeostasis of phosphatidylcholine and lysophosphatidylcholine in nervous tissues of mice was not disrupted after administration of tri-o-cresyl phosphate," Toxicological Sciences, vol. 109, no. 2, pp. 276-285, 2009.

[28] B. Fugetsu and B. Parvin, "Graphene phytotoxicity in the seedling stage of cabbage, tomato, red spinach, and lettuce," in Carbon Nanotubes-From Research to Applications, S. Bianco, Ed., CC BY-NC-SA, 2011.

[29] M. O. Sahar, "Antifungal activity of silver and copper nanoparticles on two plant pathogens, alternaria alternata and botrytis cinerea," Research Journal of Microbiology, vol. 9, pp. 34-42, 2014.

[30] G. W. Stephen, H. Li, H. Jennifer, C. Da-Ren, K. In-Chul, and J. T. Yinjie, "Phytotoxicity of metal oxide nanoparticles is related to both dissolved metals ions and adsorption of particles on seed surfaces," Journal of Petroleum \& Environmental Biotechnology, vol. 3, article 4, 2012.

[31] L. Sooyeon, K. Sunghyun, K. Saeyeon, and L. Insook, "Assessment of phytotoxicity of ZnO NPs on a medicinal plant, Fagopyrum esculentum," Environmental Science and Pollution Research, vol. 20, no. 2, pp. 848-854, 2013.

[32] R. J. Aitken, M. Q. Chaudhry, A. B. A. Boxall, and M. Hull, "Manufacture and use of nanomaterials: current status in the UK and global trends," Occupational Medicine, vol. 56, no. 5, pp. 300-306, 2006.

[33] F. Chekin, S. Bagheri, and S. B. Abd Hamid, "Synthesis of Pt doped $\mathrm{TiO}_{2}$ nanoparticles: characterization and application for electrocatalytic oxidation of 1-methionine," Sensors and Actuators B: Chemical, vol. 177, pp. 898-903, 2013.

[34] S. Bagheri, K. Shameli, and S. B. Abd Hamid, "Synthesis and characterization of anatase titanium dioxide nanoparticles using egg white solution via Sol-Gel method," Journal of Chemistry, vol. 2013, Article ID 848205, 5 pages, 2013. 
[35] F. Chekin, S. Bagheri, and S. B. Abd Hamid, "Electrochemistry and electrocatalysis of cobalt(II) immobilized onto gelassisted synthesized zinc oxide nanoparticle-multi wall carbon nanotube-polycaprolactone composite film: application to determination of glucose," Analytical Methods, vol. 4, no. 8, pp. 2423-2428, 2012.

[36] L. Ye, K. Yong, L. Liu et al., "A pilot study in non-human primates shows no adverse response to intravenous injection of quantum dots," Nature Nanotechnology, vol. 7, no. 7, pp. 453458, 2012.

[37] K. D. Grieger, S. F. Hansen, and A. Baun, “The known unknowns of nanomaterials: describing and characterizing uncertainty within environmental, health and safety risks," Nanotoxicology, vol. 3, no. 3, pp. 222-233, 2009.

[38] L. Zhang and M. Fang, "Nanomaterials in pollution trace detection and environmental improvement," Nano Today, vol. 5, no. 2, pp. 128-142, 2010.

[39] D. O. Alexis, M. Tyronne, C. Joseph, H. Indy, and H. H. Barbara, "Nanotoxicology: characterizing the scientific literature, 20002007," Journal of Nanoparticle Research, vol. 11, no. 2, pp. 251-257, 2009.

[40] L. Igor, E. B. Matthew, J. C. Laure, P. S. Thomas, and J. M. Keisler, "A decision-directed approach for prioritizing research into the impact of nanomaterials on the environment and human health," Nature Nanotechnology, vol. 6, no. 12, pp. 784-787, 2011.

[41] M. P. Holsapple, W. H. Farland, T. D. Landry et al., "Research strategies for safety evaluation of nanomaterials, part II: toxicological and safety evaluation of nanomaterials, current challenges and data needs," Toxicological Sciences, vol. 88, no. 1, pp. 12-17, 2005.

[42] K. Thomas, P. Aguar, H. Kawasaki, J. Morris, J. Nakanishi, and N. Savage, "Research strategies for safety evaluation of nanomaterials, part VIII: international efforts to develop risk-based safety evaluations for nanomaterials," Toxicological Sciences, vol. 92, no. 1, pp. 23-32, 2006.

[43] T. Thomas, K. Thomas, N. Sadrieh, N. Savage, P. Adair, and R. Bronaugh, "Research strategies for safety evaluation of nanomaterials, part VII: evaluating consumer exposure to nanoscale materials," Toxicological Sciences, vol. 91, no. 1, pp. 14-19, 2006.

[44] S. F. Hansen, E. S. Michelson, A. Kamper, P. Borling, F. StuerLauridsen, and A. Baun, "Categorization framework to aid exposure assessment of nanomaterials in consumer products," Ecotoxicology, vol. 17, no. 5, pp. 438-447, 2008.

[45] J. S. Tsuji, A. D. Maynard, P. C. Howard et al., "Research strategies for safety evaluation of nanomaterials, part IV: risk assessment of nanoparticles," Toxicological Sciences, vol. 89, no. 1, pp. 42-50, 2006.

[46] W. P. Kevin, C. B. Scott, B. K. Vijay, C. W. Scott, B. M. Moudgil, and S. M. Roberts, "Research strategies for safety evaluation of nanomaterials. Part VI. Characterization of nanoscale particles for toxicological evaluation," Toxicological Sciences, vol. 90, no. 2, pp. 296-303, 2006.

[47] N. Savage, T. A. Thomas, and J. S. Duncan, "Nanotechnology applications and implications research supported by the US Environmental Protection Agency STAR grants program," Journal of Environmental Monitoring, vol. 9, no. 10, pp. 1046-1054, 2007.

[48] G. Bystrzejewska-Piotrowska, J. Golimowski, and P. L. Urban, "Nanoparticles: their potential toxicity, waste and environmental management," Waste Management, vol. 29, no. 9, pp. 2587$2595,2009$.
[49] X. Xia, N. A. Monteiro-Riviere, and J. E. Riviere, "An index for characterization of nanomaterials in biological systems," Nature Nanotechnology, vol. 5, no. 9, pp. 671-675, 2010.

[50] N. J. Walker and J. R. Bucher, "A 21st century paradigm for evaluating the health hazards of nanoscale materials?" Toxicological Sciences, vol. 110, no. 2, pp. 251-254, 2009.

[51] J. Sanchís, M. Farré, and D. Barceló, "Analysis and fate of organic nanomaterials in environmental samples," in Analysis and Risk of Nanomaterials in Environmental and Food Samples, pp. 131$168,2012$.

[52] S. K. Sohaebuddin, P. T. Thevenot, D. Baker, J. W. Eaton, and L. Tang, "Nanomaterial cytotoxicity is composition, size, and cell type dependent," Particle and Fibre Toxicology, vol. 7, article 22, 2010.

[53] S. F. Hansen, "A global view of regulations affecting nanomaterials," Wiley Interdisciplinary Reviews: Nanomedicine and Nanobiotechnology, vol. 2, no. 5, pp. 441-449, 2010.

[54] K. C. Elliott, "Nanomaterials and the precautionary principle," Environmental Health Perspectives, vol. 119, no. 6, pp. A240A245, 2011.

[55] G. Lidén, "The European commission tries to define nanomaterials," Annals of Occupational Hygiene, vol. 55, no. 1, pp. 1-5, 2011.

[56] C. Potera, "Nanomaterials: transformation of silver nanoparticles in sewage sludge," Environmental Health Perspectives, vol. 118, no. 12, pp. A526-A527, 2010.

[57] H. Stamm, N. Gibson, and E. Anklam, "Detection of nanomaterials in food and consumer products: bridging the gap from legislation to enforcement," Food Additives and Contaminants A, vol. 29, no. 8, pp. 1175-1182, 2012.

[58] T. Kreider and W. Halperin, "Engineered nanomaterials: learning from the past, planning for the future," Journal of Occupational and Environmental Medicine, vol. 53, no. 6, pp. S108-S112, 2010.

[59] N. Musee, "Nanowastes and the environment: potential new waste management paradigm," Environment International, vol. 37, no. 1, pp. 112-128, 2011.

[60] H. S. Foss, A. Baun, E. S. Michelson, A. Kamper, P. Borling, and F. Stuer-Lauridsen, "Nanomaterials in consumer products," Nanomaterials: Risks and Benefits, pp. 359-367, 2009.

[61] J. G. Robert, H. Kelly, D. D. Nancy, and S. B. Davis, "Comparison of molecular and histological changes in zebrafish gills exposed to metallic nanoparticles," Toxicological Sciences, vol. 107, no. 2, pp. 404-415, 2009.

[62] S. Bandyopadhyay, J. R. Peralta-Videa, and J. L. GardeaTorresdey, "Advanced analytical techniques for the measurement of nanomaterials in food and agricultural samples: a review," Environmental Engineering Science, vol. 30, no. 3, pp. 118-125, 2013.

[63] P. P. Nadiminti, Y. D. Dong, C. Sayer et al., "Nanostructured liquid crystalline particles as an alternative delivery vehicle for plant agrochemicals," ACS Applied Materials and Interfaces, vol. 5, no. 5, pp. 1818-1826, 2013.

[64] E. Lombi, B. Nowack, A. Baun, and S. P. McGrath, "Evidence for effects of manufactured nanomaterials on crops is inconclusive," Proceedings of the National Academy of Sciences of the United States of America, vol. 109, no. 49, Article ID E3336, 2012.

[65] B. A. Nevius, Y. P. Chen, J. L. Ferry, and A. W. Decho, "Surfacefunctionalization effects on uptake of fluorescent polystyrene nanoparticles by model biofilms," Ecotoxicology, vol. 21, no. 8, pp. 2205-2213, 2012. 
[66] H. Bagheri, Z. Ayazi, A. Es'haghi, and A. Aghakhani, "Reinforced polydiphenylamine nanocomposite for microextraction in packed syringe of various pesticides," Journal of Chromatography A, vol. 1222, pp. 13-21, 2012.

[67] V. Ghormade, M. V. Deshpande, and K. M. Paknikar, "Perspectives for nano-biotechnology enabled protection and nutrition of plants," Biotechnology Advances, vol. 29, no. 6, pp. 792-803, 2011.

[68] P. Khiew, W. Chiu, T. Tan, S. Radiman, R. Abd-Shukor, and C. H. Chia, "Capping effect of palm-oil based organometallic ligand towards the production of highly monodispersed nanostructured material," in Palm Oil: Nutrition, Uses and Impacts, pp. 189-219, Nova Science, 2011.

[69] F. Hassan, A. Shahram, A. Farzin, and J. P. Saeed, "Comparative effects of nanosized and bulk titanium dioxide concentrations on medicinal plant salvia officinalis L," Annual Review \& Research in Biology, vol. 3, no. 4, pp. 814-824, 2013.

[70] R. Nair, S. H. Varghese, B. G. Nair, T. Maekawa, Y. Yoshida, and D. S. Kumar, "Nanoparticulate material delivery to plants," Plant Science, vol. 179, no. 3, pp. 154-163, 2010.

[71] N. Zhang, Q. Ring, G. Huang, X. Han, Y. Cheng, and W. Xu, "Transport characteristics of wheat germ agglutinin-modified insulin-liposomes and solid lipid nanoparticles in a perfused rat intestinal model," Journal of Nanoscience and Nanotechnology, vol. 6, no. 9-10, pp. 2959-2966, 2006.

[72] F. Lai, S. A. Wissing, R. H. Müller, and A. M. Fadda, "Artemisia arborescens L essential oil-loaded solid lipid nanoparticles for potential agricultural application: preparation and characterization," AAPS PharmSciTech, vol. 7, no. 1, article 2, 2006.

[73] R. De La Torre-Roche, J. Hawthorne, Y. Deng et al., "Multiwalled carbon nanotubes and $\mathrm{C}_{60}$ fullerenes differentially impact the accumulation of weathered pesticides in four agricultural plants," Environmental Science and Technology, vol. 47, no. 21, pp. 12539-12547, 2013.

[74] S. M. A. Santos, A. M. Dinis, D. M. F. Rodrigues, F. Peixoto, R. A. Videira, and A. S. Jurado, "Studies on the toxicity of an aqueous suspension of $\mathrm{C}_{60}$ nanoparticles using a bacterium (gen. Bacillus) and an aquatic plant (Lemna gibba) as in vitro model systems," Aquatic Toxicology, vol. 142-143, pp. 347-354, 2013.

[75] Q. Liu, X. Zhang, Y. Zhao et al., "Fullerene-induced increase of glycosyl residue on living plant cell wall," Environmental Science and Technology, vol. 47, no. 13, pp. 7490-7498, 2013.

[76] R. De La Torre-Roche, J. Hawthorne, Y. Deng et al., "Fullereneenhanced accumulation of $\mathrm{p}, \mathrm{p} /$-DDE in agricultural crop species," Environmental Science and Technology, vol. 46, no. 17, pp. 9315-9323, 2012.

[77] J. Gao, Y. Wang, K. M. Folta et al., "Polyhydroxy fullerenes (fullerols or fullerenols): beneficial effects on growth and lifespan in diverse biological models," PLoS ONE, vol. 6, no. 5, Article ID e19976, 2011.

[78] Q. Liu, Y. Zhao, Y. Wan et al., "Study of the inhibitory effect of water-soluble fullerenes on plant growth at the cellular level," ACS Nano, vol. 4, no. 10, pp. 5743-5748, 2010.

[79] C. Kole, P. Kole, K. M. Randunu et al., "Nanobiotechnology can boost crop production and quality: First evidence from increased plant biomass, fruit yield and phytomedicine content in bitter melon (Momordica charantia)," BMC Biotechnology, vol. 13, article 37, 2013.

[80] W. Z. Li, S. S. Xie, L. X. Qian et al., "Large-scale synthesis of aligned carbon nanotubes," Science, vol. 274, no. 5293, pp. 1701$1703,1996$.
[81] G. C. Philip, B. Keith, I. Masa, and A. Zettl, "Extreme oxygen sensitivity of electronic properties of carbon nanotubes," Science, vol. 287, no. 5459, pp. 1801-1804, 2000.

[82] M. K. Mani, G. Viola, M. J. Reece, J. P. Hall, and S. L. Evans, "Fabrication of carbon nanotube reinforced iron based magnetic alloy composites by spark plasma sintering," Journal of Alloys and Compounds, vol. 601, pp. 146-153, 2014.

[83] A. Hazarika and T. K. Maji, "Strain sensing behavior and dynamic mechanical properties of carbon nanotubes/nanoclay reinforced wood polymer nanocomposite," Chemical Engineering Journal, vol. 247, pp. 33-41, 2014.

[84] D. Liu, Y. Zhang, X. Sun, and P. R. Chang, "Recent advances in bio-sourced polymeric carbohydrate/nanotube composites," Journal of Applied Polymer Science, vol. 131, no. 12, 2014.

[85] M. Chai, F. Shi, R. Li, L. Liu, Y. Liu, and F. Liu, "Interactive effects of cadmium and carbon nanotubes on the growth and metal accumulation in a halophyte Spartina alterniflora (Poaceae)," Plant Growth Regulation, vol. 71, no. 2, pp. 171-179, 2013.

[86] M. V. Khodakovskaya, B. Kim, J. N. Kim et al., "Carbon nanotubes as plant growth regulators: effects on tomato growth, reproductive system, and soil microbial community," Small, vol. 9, no. 1, pp. 115-123, 2013.

[87] Z. Long, J. Ji, K. Yang, D. Lin, and F. Wu, "Systematic and quantitative investigation of the mechanism of carbon nanotubes' toxicity toward Algae," Environmental Science and Technology, vol. 46, no. 15, pp. 8458-8466, 2012.

[88] C. Lin, B. Fugetsu, Y. Su, and F. Watari, "Studies on toxicity of multi-walled carbon nanotubes on Arabidopsis T87 suspension cells," Journal of Hazardous Materials, vol. 170, no. 2-3, pp. 578583, 2009.

[89] C.-X. Shen, Q.-F. Zhang, J. Li, F.-C. Bi, and N. Yao, "Induction of programmed cell death in Arabidopsis and rice by single-wall carbon nanotubes," American Journal of Botany, vol. 97, no. 10, pp. 1602-1609, 2010.

[90] M. V. Khodakovskaya, K. De Silva, A. S. Biris, E. Dervishi, and H. Villagarcia, "Carbon nanotubes induce growth enhancement of tobacco cells," ACS Nano, vol. 6, no. 3, pp. 2128-2135, 2012.

[91] H. Yi, S. Nisar, S. Lee et al., "Patterned assembly of genetically modified viral nanotemplates via nucleic acid hybridization," Nano Letters, vol. 5, no. 10, pp. 1931-1936, 2005.

[92] J. E. Cañas, M. Long, S. Nations et al., "Effects of functionalized and nonfunctionalized single-walled carbon nanotubes on root elongation of select crop species," Environmental Toxicology and Chemistry, vol. 27, no. 9, pp. 1922-1931, 2008.

[93] P. C. Ke and M. H. Lamm, "A biophysical perspective of understanding nanoparticles at large," Physical Chemistry Chemical Physics, vol. 13, no. 16, pp. 7273-7283, 2011.

[94] G. Ghodake, Y. D. Seo, D. Park, and D. S. Lee, "Phytotoxicity of carbon nanotubes assessed by brassica juncea and phaseolus mungo," Journal of Nanoelectronics and Optoelectronics, vol. 5, no. 2, pp. 157-160, 2010.

[95] M. Khodakovskaya, E. Dervishi, M. Mahmood et al., "Carbon nanotubes are able to penetrate plant seed coat and dramatically affect seed germination and plant growth," ACS Nano, vol. 3, no. 10, pp. 3221-3227, 2009.

[96] Y. Lin, A. M. Rao, B. Sadanadan, E. A. Kenik, and Y.-P. Sun, "Functionalizing multiple-walled carbon nanotubes with aminopolymers," Journal of Physical Chemistry B, vol. 106, no. 6, pp. 1294-1298, 2002.

[97] J. Muller, F. Huaux, N. Moreau et al., "Respiratory toxicity of multi-wall carbon nanotubes," Toxicology and Applied Pharmacology, vol. 207, no. 3, pp. 221-231, 2005. 
[98] H. Kong, C. Gao, and D. Yan, "Controlled functionalization of multiwalled carbon nanotubes by in situ atom transfer radical polymerization," Journal of the American Chemical Society, vol. 126, no. 2, pp. 412-413, 2004.

[99] H. J. Li, W. G. Lu, J. J. Li, X. D. Bai, and C. Z. Gu, "Multichannel ballistic transport in multiwall carbon nanotubes," Physical Review Letters, vol. 95, no. 8, Article ID 086601, 2005.

[100] F. Chekin, S. Bagheri, A. K. Arof, and S. B. A. Hamid, "Preparation and characterization of $\mathrm{Ni}$ (II)/polyacrylonitrile and carbon nanotube composite modified electrode and application for carbohydrates electrocatalytic oxidation," Journal of Solid State Electrochemistry, vol. 16, no. 10, pp. 3245-3251, 2012.

[101] X. Wang, H. Han, X. Liu, X. Gu, K. Chen, and D. Lu, "Multiwalled carbon nanotubes can enhance root elongation of wheat (Triticum aestivum) plants," Journal of Nanoparticle Research, vol. 14, no. 6, article 841, 2012.

[102] E. Smirnova, A. Gusev, O. Zaytseva et al., "Uptake and accumulation of multiwalled carbon nanotubes change the morphometric and biochemical characteristics of Onobrychis arenaria seedlings," Frontiers of Chemical Science and Engineering, vol. 6, no. 2, pp. 132-138, 2012.

[103] X.-M. Tan and B. Fugetsu, "Multi-walled carbon nanotubes interact with cultured rice cells: evidence of a self-defense response," Journal of Biomedical Nanotechnology, vol. 3, no. 3, pp. 285-288, 2007.

[104] D. Stampoulis, S. K. Sinha, and J. C. White, "Assay-dependent phytotoxicity of nanoparticles to plants," Environmental Science and Technology, vol. 43, no. 24, pp. 9473-9479, 2009.

[105] D. Ren, Z. Guo, F. Du, J. Zheng, and Y. Chen, "A nanohybrid material of SWNTs covalently functionalized with porphyrin for light harvesting antenna: Synthesis and photophysical properties," Journal of Nanoscience and Nanotechnology, vol. 7, no. 4-5, pp. 1539-1545, 2007.

[106] K. Hata, D. N. Futaba, K. Mizuno, T. Namai, M. Yumura, and S. Iijima, "Water-assisted highly efficient synthesis of impurityfree single-walled carbon nanotubes," Science, vol. 306, no. 5700, pp. 1362-1364, 2004.

[107] A. Parise, H. Thakor, and X. Zhang, "Activity inhibition on municipal activated sludge by single-walled carbon nanotubes," Journal of Nanoparticle Research, vol. 16, no. 1, article 2159, 2014.

[108] D. Flores, J. S. Chaves, R. Chacon, and A. Schmidt, "A novel technique using SWCNTs to enhanced development and root growth of fig plants (Ficus carica)," in Technical Proceedings of the NSTI Nanotechnology Conference and Expo (NSTI-Nanotech '13), vol. 3, pp. 167-170, Washington, DC, USA, May 2013.

[109] S. Yan, L. Zhao, H. Li et al., "Single-walled carbon nanotubes selectively influence maize root tissue development accompanied by the change in the related gene expression," Journal of Hazardous Materials, vol. 246-247, pp. 110-118, 2013.

[110] D. Cui, H. Yuan, X. Zhang et al., "Effects of single walled carbon nanotubes on Arabidopsis mesophyll cells," ECS Transactions, vol. 41, no. 40, pp. 43-48, 2012.

[111] J. Chen, Y. Hao, X. Yang et al., "Fitc delivery into plant cells using magnetic single-walled carbon nanotubes," Journal of Nanoscience and Nanotechnology, vol. 12, no. 8, pp. 6287-6293, 2012.

[112] J. C. Lou, M. J. Jung, H. W. Yang, J. Y. Han, and W. H. Huang, "Removal of dissolved organic matter (DOM) from raw water by single-walled carbon nanotubes (SWCNTs)," Journal of Environmental Science and Health-Part A Toxic/Hazardous Substances and Environmental Engineering, vol. 46, no. 12, pp. 1357-1365, 2011.
[113] H. Yuan, S. Hu, P. Huang et al., "Single walled carbon nanotubes exhibit dual-phase regulation to exposed Arabidopsis mesophyll cells," Nanoscale Research Letters, vol. 6, no. 1, pp. 1-9, 2011.

[114] H. Yuan, S. Hu, P. Huang et al., "Single walled carbon nanotubes exhibit dual-phase regulation to exposed arabidopsis mesophyll cells," Nanoscale Research Letters, vol. 7, article 44, pp. 1-9, 2012.

[115] C. Shen, Q. Zhang, J. Li, F. Bi, and N. Yao, "Induction of programmed cell death in Arabidopsis and rice by single-wall carbon nanotubes," American Journal of Botany, vol. 97, no. 10, pp. 1602-1609, 2010.

[116] M. Soylak and Y. E. Unsal, "Chromium and iron determinations in food and herbal plant samples by atomic absorption spectrometry after solid phase extraction on single-walled carbon nanotubes (SWCNTs) disk," Food and Chemical Toxicology, vol. 48, no. 6, pp. 1511-1515, 2010.

[117] P. Begum, R. Ikhtiari, and B. Fugetsu, "Graphene phytotoxicity in the seedling stage of cabbage, tomato, red spinach, and lettuce," Carbon, vol. 49, no. 12, pp. 3907-3919, 2011.

[118] A. A.-G. Ahmed, R.-K. Guptab, P. K. Kaholc et al., "Improved solar efficiency by introducing graphene oxide in purple cabbage dye sensitized $\mathrm{TiO}_{2}$ based solar cell," Solid State Communications, vol. 183, pp. 56-59, 2014.

[119] X. Ye, Y. Gu, and C. Wang, "Fabrication of the $\mathrm{Cu}_{2} \mathrm{O} /$ polyvinyl pyrrolidone-graphene modified glassy carbon-rotating disk electrode and its application for sensitive detection of herbicide paraquat," Sensors and Actuators B, vol. 173, pp. 530-539, 2012.

[120] M. Mehdi, A. Mohammad, and A. F. Mohammad, "Safety concerns to application of graphene compounds in pharmacy and medicine," DARU Journal of Pharmaceutical Sciences, vol. 22, pp. 23-30, 2014.

[121] O. Akhavan and E. Ghaderi, "Toxicity of graphene and graphene oxide nanowalls against bacteria," ACS Nano, vol. 4, no. 10, pp. 5731-5736, 2010.

[122] A. Sasidharan, L. S. Panchakarla, P. Chandran et al., "Differential nano-bio interactions and toxicity effects of pristine versus functionalized graphene," Nanoscale, vol. 3, no. 6, pp. 24612464, 2011.

[123] N. A. Anjum, N. Singh, M. K. Singh et al., "Single-bilayer graphene oxide sheet impacts and underlying potential mechanism assessment in germinating faba bean (Vicia faba $L$.)," Science of the Total Environment, vol. 472, pp. 834-841, 2014.

[124] G. Lee and B. S. Kim, "Biological reduction of graphene oxide using plant leaf extracts," Biotechnology Progress, vol. 30, no. 2, pp. 463-469, 2014.

[125] B. S. Kim, "Biological synthesis of nanomaterials using plant leaf extracts," in Proceedings of the 13th IEEE International Conference on Nanotechnology, pp. 1204-1207, Beijing, China, August 2013.

[126] P. Begum and B. Fugetsu, "Induction of cell death by graphene in Arabidopsis thaliana (Columbia ecotype) T87 cell suspensions," Journal of Hazardous Materials, vol. 260, pp. 1032-1041, 2013.

[127] N. A. Anjum, N. Singh, M. K. Singh et al., "Single-bilayer graphene oxide sheet tolerance and glutathione redox system significance assessment in faba bean (Vicia faba L.)," Journal of Nanoparticle Research, vol. 15, no. 7, article 1770, 2013.

[128] I. Ocsoy, M. L. Paret, M. A. Ocsoy et al., "Nanotechnology in plant disease management: DNA-directed silver nanoparticles on graphene oxide as an antibacterial against Xanthomonas perforans," ACS Nano, vol. 7, no. 10, pp. 8972-8980, 2013. 
[129] M. Niederberger, "Nonaqueous sol-gel routes to metal oxide nanoparticles," Accounts of Chemical Research, vol. 40, no. 9, pp. 793-800, 2007.

[130] M. E. Franke, T. J. Koplin, and U. Simon, "Metal and metal oxide nanoparticles in chemiresistors: Does the nanoscale matter?" Small, vol. 2, no. 1, pp. 36-50, 2006.

[131] A. Kolmakov and M. Moskovits, "Chemical sensing and catalysis by one-dimensional metal-oxide nanostructures," Annual Review of Materials Research, vol. 34, pp. 151-180, 2004.

[132] P. K. Stoimenov, R. L. Klinger, G. L. Marchin, and K. J. Klabunde, "Metal oxide nanoparticles as bactericidal agents," Langmuir, vol. 18, no. 17, pp. 6679-6686, 2002.

[133] M. Niederberger, G. Garnweitner, J. Buha, J. Polleux, J. Ba, and N. Pinna, "Nonaqueous synthesis of metal oxide nanoparticles: review and indium oxide as case study for the dependence of particle morphology on precursors and solvents," Journal of SolGel Science and Technology, vol. 40, no. 2-3, pp. 259-266, 2006.

[134] M. Anna, G. N. Albert, and I. K. Esko, "The role of metal nanoparticles in the catalytic production of single-walled carbon nanotubes-a review," Journal of Physics, vol. 15, no. 42, p. S3011, 2003.

[135] V. I. Karamushka and G. M. Gadd, "Interaction of Saccharomyces cerevisiae with gold: toxicity and accumulation," BioMetals, vol. 12, no. 4, pp. 289-294, 1999.

[136] J. M. Catherine, M. G. Anand, W. S. John et al., "Gold nanoparticles in biology: beyond toxicity to cellular imaging," Accounts of Chemical Research, vol. 41, no. 12, pp. 1721-1730, 2008.

[137] C. M. Goodman, C. D. McCusker, T. Yilmaz, and V. M. Rotello, "Toxicity of gold nanoparticles functionalized with cationic and anionic side chains," Bioconjugate Chemistry, vol. 15, no. 4, pp. 897-900, 2004.

[138] E. Boisselier and D. Astruc, "Gold nanoparticles in nanomedicine: preparations, imaging, diagnostics, therapies and toxicity," Chemical Society Reviews, vol. 38, no. 6, pp. 1759-1782, 2009.

[139] T. S. Hauck, A. A. Ghazani, and W. C. W. Chan, "Assessing the effect of surface chemistry on gold nanorod uptake, toxicity, and gene expression in mammalian cells," Small, vol. 4, no. 1, pp. 153-159, 2008.

[140] N. Khlebtsov and L. Dykman, "Biodistribution and toxicity of engineered gold nanoparticles: a review of in vitro and in vivo studies," Chemical Society Reviews, vol. 40, no. 3, pp. 1647-1671, 2011.

[141] H. J. Johnston, G. Hutchison, F. M. Christensen, S. Peters, S. Hankin, and V. Stone, "A review of the in vivo and in vitro toxicity of silver and gold particulates: particle attributes and biological mechanisms responsible for the observed toxicity," Critical Reviews in Toxicology, vol. 40, no. 4, pp. 328-346, 2010.

[142] C. Saison, F. Perreault, J. Daigle et al., "Effect of core-shell copper oxide nanoparticles on cell culture morphology and photosynthesis (photosystem II energy distribution) in the green alga, Chlamydomonas reinhardtii," Aquatic Toxicology, vol. 96, no. 2, pp. 109-114, 2010.

[143] F. Perreault, N. Bogdan, M. Morin, J. Claverie, and R. Popovic, "Interaction of gold nanoglycodendrimers with algal cells (Chlamydomonas reinhardtii) and their effect on physiological processes," Nanotoxicology, vol. 6, no. 2, pp. 109-120, 2012.

[144] Z. Guangshu, S. W. Katherine, W. P. David, J. J. A. Pedro, and L. S. Jerald, "Transport of gold nanoparticles through plasmodesmata and precipitation of gold Ions in woody poplar,"
Environment science Technology Letter, vol. 1, no. 2, pp. 146-151, 2014.

[145] S. Arora, P. Sharma, S. Kumar, R. Nayan, P. K. Khanna, and M. G. H. Zaidi, "Gold-nanoparticle induced enhancement in growth and seed yield of Brassica juncea," Plant Growth Regulation, vol. 66, no. 3, pp. 303-310, 2012.

[146] J. L. Gardea-Torresdey, K. J. Tiemann, G. Gamez et al., "Reduction and accumulation of gold (III) by Medicago sativa alfalfa biomass: X-ray absorption spectroscopy, $\mathrm{pH}$, and temperature dependence," Environmental Science \& Technology, vol. 34, no. 20, pp. 4392-4396, 2000.

[147] S. Green and S. Renault, "Influence of papermill sludge on growth of Medicago sativa, Festuca rubra and Agropyron trachycaulum in gold mine tailings: a greenhouse study," Environmental Pollution, vol. 151, no. 3, pp. 524-531, 2008.

[148] D. Feretti, I. Zerbini, C. Zani, E. Ceretti, M. Moretti, and S. Monarca, "Allium cepa chromosome aberration and micronucleus tests applied to study genotoxicity of extracts from pesticide-treated vegetables and grapes," Food Additives and Contaminants, vol. 24, no. 6, pp. 561-572, 2007.

[149] P. A. Wagner, W. G. Hoekstra, and H. E. Ganther, "Alleviation of silver toxicity by selenite in the rat in relation to tissue glutathione peroxidase," Proceedings of the Society for Experimental Biology and Medicine, vol. 148, no. 4, pp. 1106-1110, 1975.

[150] C. Hogstrand, F. Galvez, and C. M. Wood, "Toxicity, silver accumulation and metallothionein induction in freshwater rainbow trout during exposure to different silver salts," Environmental Toxicology and Chemistry, vol. 15, no. 7, pp. 1102-1108, 1996.

[151] G. Fernando and M. W. Chris, "The relative importance of water hardness and chloride levels in modifying the acute toxicity of silver to rainbow trout (Oncorhynchus mykiss)," Environmental Toxicology and Chemistry, vol. 16, no. 11, pp. 2363-2368, 1997.

[152] A. F. Elizabeth and H. Christer, "Acute silver toxicity to seawater-acclimated rainbow trout: influence of salinity on toxicity and silver speciation," Environmental Toxicology and Chemistry, vol. 17, no. 4, pp. 589-593, 1998.

[153] D. Lee, C. Fortin, and P. G. C. Campbell, "Contrasting effects of chloride on the toxicity of silver to two green algae, Pseudokirchneriella subcapitata and Chlamydomonas reinhardtii," Aquatic Toxicology, vol. 75, no. 2, pp. 127-135, 2005.

[154] C. M. Wood, C. Hogstrand, F. Galvez, and R. S. Munger, "The physiology of waterborne silver toxicity in freshwater rainbow trout (Oncorhynchus mykiss) 1. The effects of ionic $\mathrm{Ag}^{+}$," Aquatic Toxicology, vol. 35, no. 2, pp. 93-109, 1996.

[155] J. C. Mcgeer, R. C. Playle, C. M. Wood, and F. Galvez, "A physiologically based biotic ligand model for predicting the acute toxicity of waterborne silver to rainbow trout in freshwaters," Environmental Science and Technology, vol. 34, no. 19, pp. 41994207, 2000.

[156] B. Adalto and M. W. Chris, "Mechanism of acute silver toxicity in Daphnia magna," Environmental Toxicology and Chemistry, vol. 22, no. 6, pp. 1361-1367, 2003.

[157] S. H. F. W. Justin and W. Armstrong, "Evidence for the involvement of ethene in aerenchyma formation in adventitious roots of rice (Oryza sativa L.)," New Phytologist, vol. 118, no. 1, pp. 49-62, 1991.

[158] B. D. Nguyen, D. S. Brar, B. C. Bui, T. V. Nguyen, L. N. Pham, and H. T. Nguyen, "Identification and mapping of the QTL for aluminum tolerance introgressed from the new source, Oryza rufipogon Griff., into indica rice (Oryza sativa L.)," Theoretical and Applied Genetics, vol. 106, no. 4, pp. 583-593, 2003. 
[159] C. Mao, K. Yi, L. Yang et al., "Identification of aluminiumregulated genes by cDNA-AFLP in rice (Oryza sativa L.): aluminium-regulated genes for the metabolism of cell wall components," Journal of Experimental Botany, vol. 55, no. 394, pp. 137-143, 2004.

[160] T. R. Hans, "Bioaccumulation and toxicity of silver compounds: a review," Environmental Toxicology and Chemistry, vol. 18, no. 1, pp. 89-108, 1999.

[161] S. J. Slade and G. F. Pegg, "The effect of silver and other metal ions on the in vitro growth of root-rotting Phytophthora and other fungal species," Annals of Applied Biology, vol. 122, no. 2, pp. 233-251, 1993.

[162] L. Yin, B. P. Colman, B. M. McGill, J. P. Wright, and E. S. Bernhardt, "Effects of silver nanoparticle exposure on germination and early growth of eleven wetland plants," PLOS ONE, vol. 7, no. 10, Article ID e47674, 2012.

[163] L. Yin, Y. Cheng, B. Espinasse et al., "More than the ions: the effects of silver nanoparticles on lolium multiflorum," Environmental Science and Technology, vol. 45, no. 6, pp. 23602367, 2011.

[164] Y. Cheng, L. Yin, S. Lin, M. Wiesner, E. Bernhardt, and J. Liu, "Toxicity reduction of polymer-stabilized silver nanoparticles by sunlight," Journal of Physical Chemistry C, vol. 115, no. 11, pp. 4425-4432, 2011.

[165] G. Howe and S. Merchant, "Heavy metal-activated synthesis of peptides in Chlamydomonas reinhardtii," Plant Physiology, vol. 98, no. 1, pp. 127-136, 1992.

[166] G. R. Paul and L. Stephen, "Purification of Hydrogenase from Chlamydomonas reinhardtiil," Plant Physiology, vol. 75, no. 3, pp. 705-709, 1984.

[167] F. Piccapietra, C. G. Allué, L. Sigg, and R. Behra, "Intracellular silver accumulation in Chlamydomonas reinhardtii upon exposure to carbonate coated silver nanoparticles and silver nitrate," Environmental Science and Technology, vol. 46, no. 13, pp. 73907397, 2012.

[168] R. Inokuchi, T. Itagaki, J. T. Wiskich, K. Nakayama, and M. Okada, "An NADP-glutamate dehydrogenase from the green alga Bryopsis maxima. Purification and properties," Plant and Cell Physiology, vol. 38, no. 3, pp. 327-335, 1997.

[169] J. Cairns Jr., A. G. Heath, and B. C. Parker, "The effects of temperature upon the toxicity of chemicals to aquatic organisms," Hydrobiologia, vol. 47, no. 1, pp. 135-171, 1975.

[170] W. Wuncheng, "Toxicity tests of aquatic pollutants by using common duckweed," Environmental Pollution B, vol. 11, no. 1, pp. 1-14, 1986.

[171] J. M. Unrine, B. P. Colman, A. J. Bone, A. P. Gondikas, and C. W. Matson, "Biotic and abiotic interactions in aquatic microcosms determine fate and toxicity of ag nanoparticles. Part 1. Aggregation and dissolution," Environmental Science and Technology, vol. 46, no. 13, pp. 6915-6924, 2012.

[172] W. A. Shoults-Wilson, B. C. Reinsch, O. V. Tsyusko, P. M. Bertsch, G. V. Lowry, and J. M. Unrine, "Role of particle size and soil type in toxicity of silver nanoparticles to earthworms," Soil Science Society of America Journal, vol. 75, no. 2, pp. 365377, 2011.

[173] J. Roh, J. S. Sang, J. Yi et al., "Ecotoxicity of silver nanoparticles on the soil nematode Caenorhabditis elegans using functional ecotoxicogenomics," Environmental Science and Technology, vol. 43, no. 10, pp. 3933-3940, 2009.

[174] C. Musante and J. C. White, "Toxicity of silver and copper to Cucurbita pepo: differential effects of nano and bulk-size particles," Environmental Toxicology, vol. 27, no. 9, pp. 510-517, 2012.

[175] D. U. Beebe and R. Turgeon, "Localization of galactinol, raffinose, and stachyose synthesis in Cucurbita pepo leaves," Planta, vol. 188, no. 3, pp. 354-361, 1992.

[176] M. Kumari, A. Mukherjee, and N. Chandrasekaran, "Genotoxicity of silver nanoparticles in Allium cepa," Science of the Total Environment, vol. 407, no. 19, pp. 5243-5246, 2009.

[177] A. Saxena, R. M. Tripathi, and R. P. Singh, "Biological synthesis of silver nanoparticles by using onion (Allium cepa) extract and their antibacterial activity," Digest Journal of Nanomaterials and Biostructures, vol. 5, no. 2, pp. 427-432, 2010.

[178] W. Lee, J. I. Kwak, and Y. An, "Effect of silver nanoparticles in crop plants Phaseolus radiatus and Sorghum bicolor: media effect on phytotoxicity," Chemosphere, vol. 86, no. 5, pp. 491-499, 2012.

[179] D. Liu, W. Jiang, W. Wang, F. Zhao, and C. Lu, "Effects of lead on root growth, cell division, and nucleolus of Allium cepa," Environmental Pollution, vol. 86, no. 1, pp. 1-4, 1994.

[180] C. O. Dimkpa, J. E. McLean, N. Martineau, D. W. Britt, R. Haverkamp, and A. J. Anderson, "Silver nanoparticles disrupt wheat (Triticum aestivum L.) growth in a sand matrix," Environmental Science and Technology, vol. 47, no. 2, pp. 1082-1090, 2013.

[181] X. J. Jiang, Y. M. Luo, Q. G. Zhao, A. J. M. Baker, P. Christie, and M. H. Wong, "Soil Cd availability to Indian mustard and environmental risk following EDTA addition to Cd-contaminated soil," Chemosphere, vol. 50, no. 6, pp. 813-818, 2003.

[182] B. B. Clarke and E. Brennan, "Differential cadmium accumulation and phytotoxicity in sixteen tobacco cultivars," Journal of the Air and Waste Management Association, vol. 39, no. 10, pp. 1319-1322, 1989.

[183] M. A. Kashem and S. Kawai, "Alleviation of cadmium phytotoxicity by magnesium in Japanese mustard spinach," Soil Science and Plant Nutrition, vol. 53, no. 3, pp. 246-251, 2007.

[184] K. Wang, "Comparative study on Cd phytotoxicity to different genes of rice," Rural Eco-Environment, vol. 12, no. 3, pp. 18-23, 1996.

[185] M. D. Groppa, E. P. Rosales, M. F. Iannone, and M. P. Benavides, "Nitric oxide, polyamines and Cd-induced phytotoxicity in wheat roots," Phytochemistry, vol. 69, no. 14, pp. 2609-2615, 2008.

[186] B. V. Somashekaraiah, K. Padmaja, and A. R. K. Prasad, "Phytotoxicity of cadmium ions on germinating seedlings of mung bean (Phaseolus vulgaris): involvement of lipid peroxides in chlorphyll degradation," Physiologia Plantarum, vol. 85, no. 1, pp. 85-89, 1992.

[187] M. K. John, C. J. VanLaerhoven, and H. H. Chuah, "Factors affecting plant uptake and phytotoxicity of cadmium added to soils," Environmental Science and Technology, vol. 6, no. 12, pp. 1005-1009, 1972.

[188] U.-H. Cho and N.-H. Seo, "Oxidative stress in Arabidopsis thaliana exposed to cadmium is due to hydrogen peroxide accumulation," Plant Science, vol. 168, no. 1, pp. 113-120, 2005.

[189] M. K. John and C. J. van Laerhoven, "Differential effects of cadmium on lettuce varieties," Environmental Pollution, vol. 10, no. 3, pp. 163-173, 1976.

[190] A. Lagriffoul, B. Mocquot, M. Mench, and J. Vangronsveld, "Cadmium toxicity effects on growth, mineral and chlorophyll contents, and activities of stress related enzymes in young maize plants (Zea mays L.)," Plant and Soil, vol. 200, no. 2, pp. 241-250, 1998. 
[191] M. A. Maine, M. V. Duarte, and N. L. Suñé, "Cadmium uptake by floating macrophytes," Water Research, vol. 35, no. 11, pp. 2629-2634, 2001.

[192] E. Lozano-Rodríguez, L. E. Hernández, P. Bonay, and R. O. Carpena-Ruiz, "Distribution of cadmium in shoot and root tissues," Journal of Experimental Botany, vol. 48, no. 306, pp. 123-128, 1997.

[193] K. K. Mishra, U. N. Rai, and O. Prakash, "Bioconcentration and phytotoxicity of Cd in Eichhornia crassipes," Environmental Monitoring and Assessment, vol. 130, no. 1-3, pp. 237-243, 2007.

[194] G. A. Mitchell, F. T. Bingham, and A. L. Page, "Yield and metal composition of lettuce and wheat grown on soils amended with sewage sludge enriched with cadmium, copper, nickel, and zinc," Journal of Environmental Quality, vol. 7, no. 2, pp. 165-171, 1977.

[195] M. S. Eva, B. Anders, K. Matthias, and T. Stefan, "Insignificant acute toxicity of $\mathrm{TiO} 2$ nanoparticles to willow trees," Journal of Soils and Sediments, vol. 9, no. 1, pp. 46-53, 2009.

[196] K. Sunada, X. G. Ding, M. S. Utami, Y. Kawashima, Y. Miyama, and K. Hashimoto, "Detoxification of phytotoxic compounds by $\mathrm{TiO}_{2}$ photocatalysis in a recycling hydroponic cultivation system of asparagus," Journal of Agricultural and Food Chemistry, vol. 56, no. 12, pp. 4819-4824, 2008.

[197] J. C. Garcia, J. I. Simionato, V. D. C. Almeida et al., "Evolutive follow-up of the photocatalytic degradation of real textile effluents in $\mathrm{TiO}_{2}$ and $\mathrm{TiO}_{2} / \mathrm{H}_{2} \mathrm{O}_{2}$ systems and their toxic effects on Lactuca sativa seedlings," Journal of the Brazilian Chemical Society, vol. 20, no. 9, pp. 1589-1597, 2009.

[198] H. Feizi, P. Rezvani Moghaddam, N. Shahtahmassebi, and A. Fotovat, "Impact of bulk and nanosized titanium dioxide $\left(\mathrm{TiO}_{2}\right)$ on wheat seed germination and seedling growth," Biological Trace Element Research, vol. 146, no. 1, pp. 101-106, 2012.

[199] H. Feizi, M. Kamali, L. Jafari, and P. Rezvani Moghaddam, "Phytotoxicity and stimulatory impacts of nanosized and bulk titanium dioxide on fennel (Foeniculum vulgare Mill)," Chemosphere, vol. 91, no. 4, pp. 506-511, 2013.

[200] M. R. Castiglione, L. Giorgetti, C. Geri, and R. Cremonini, “The effects of nano- $\mathrm{TiO}_{2}$ on seed germination, development and mitosis of root tip cells of Vicia narbonensis L. and Zea mays L," Journal of Nanoparticle Research, vol. 13, no. 6, pp. 2443-2449, 2011.

[201] Z. Qiu, Q. Yang, and W. Liu, "Photocatalytic degradation of phytotoxic substances in waste nutrient solution by various immobilized levels of nano-TiO ${ }_{2}$," Water, Air \& Soil Pollution, vol. 224, no. 3, pp. 1-10, 2013.

[202] S. Uhram, S. Minjoo, L. Gisuk, R. Jinkyu, K. Younghun, and J. L. Eun, "Functional analysis of $\mathrm{TiO} 2$ nanoparticle toxicity in three plant species," Biological Trace Element Research, vol. 155, no. 1, pp. 93-103, 2013.

[203] F. Hasan, R. M. Parviz, S. Nasser, and F. Amir, "Effects of concentrations of bulk and nanosized titanium dioxide $\left(\mathrm{TiO}_{2}\right)$ on germination of wheat seed," in Proceedings of the International Congress on Nanoscience \& Nanotechnology (ICNN '12), pp. 1-10, Kashan, Iran, September 2012.

[204] M. Homa, A. Reyhaneh, and N. Mohsen, "Physiological effects of $\mathrm{TiO}_{2}$ nanoparticles on wheat (Triticum aestivum)," Technical Journal Engineering \& Applied Science, vol. 3, no. 14, pp. 13651370, 2013.

[205] J. Kurepa, T. Paunesku, S. Vogt et al., "Uptake and distribution of ultrasmall anatase $\mathrm{TiO}_{2}$ alizarin red $\mathrm{S}$ nanoconjugates in arabidopsis thaliana," Nano Letters, vol. 10, no. 7, pp. 2296-2302, 2010.
[206] M. Homa and A. Reyhane, "Effect on germination and early growth characteristics in wheat plants (Triticumaestivum L.) seeds exposed to $\mathrm{TiO}_{2}$ nanoparticles," Journal of Chemical Health Risks, vol. 4, no. 1, pp. 1-10, 2014.

[207] K. Elghniji, O. Hentati, N. Mlaik, A. Mahfoudh, and M. Ksibi, "Photocatalytic degradation of 4-chlorophenol under Pmodified $\mathrm{TiO}_{2}$ /UV system: kinetics, intermediates, phytotoxicity and acute toxicity," Journal of Environmental Sciences, vol. 24, no. 3, pp. 479-487, 2012.

[208] S. Wang, J. Kurepa, and J. A. Smalle, "Ultra-small $\mathrm{TiO}_{2}$ nanoparticles disrupt microtubular networks in Arabidopsis thaliana," Plant, Cell \& Environment, vol. 34, no. 5, pp. 811-820, 2011.

[209] M. L. Paret, G. E. Vallad, D. R. Averett, J. B. Jones, and S. M. Olson, "Photocatalysis: effect of light-activated nanoscale formulations of $\mathrm{TiO}_{2}$ on Xanthomonas perforans and control of bacterial spot of tomato," Phytopathology, vol. 103, no. 3, pp. 228-236, 2013.

[210] G. Song, Y. Gao, H. Wu, W. Hou, C. Zhang, and H. Ma, "Physiological effect of anatase $\mathrm{TiO}_{2}$ nanoparticles on Lemna minor," Environmental Toxicology and Chemistry, vol. 31, no. 9, pp. 2147-2152, 2012.

[211] J. Wang, S. Chen, X. Quan, H. Zhao, and Y. Zhao, "Enhanced photodegradation of PNP on soil surface under UV irradiation with $\mathrm{TiO}_{2}$," Soil and Sediment Contamination, vol. 16, no. 4, pp. 413-421, 2007.

[212] A. R. Khataee, M. Fathinia, A. Naseri et al., "Modeling and optimization of simultaneous photocatalysis of three dyes on ceramic-coated $\mathrm{TiO}_{2}$ nanoparticles using chemometrics methods: phytotoxicological assessment during degradation process," Research on Chemical Intermediates, vol. 40, no. 3, pp. 1283-1302, 2014.

[213] C. Larue, G. Veronesi, A. Flank, S. Surble, N. Herlin-Boime, and M. Carrière, "Comparative uptake and impact of $\mathrm{TiO}_{2}$ nanoparticles in wheat and rapeseed," Journal of Toxicology and Environmental Health A: Current Issues, vol. 75, no. 13-15, pp. 722-734, 2012.

[214] E. H. Dehkourdi and M. Mosavi, "Effect of anatase nanoparticles $\left(\mathrm{TiO}_{2}\right)$ on parsley seed germination (Petroselinum crispum) in vitro," Biological Trace Element Research, vol. 155, no. 2, pp. 283-286, 2013.

[215] Q. Mingfang, L. Yufeng, and L. Tianlai, "Nano- $\mathrm{TiO}_{2}$ improve the photosynthesis of tomato leaves under mild heat stress, biological trace element research," Biological Trace Element Research, vol. 156, no. 1, pp. 323-328, 2013.

[216] K. Hund-Rinke and M. Simon, "Ecotoxic effect of photocatalytic active nanoparticles $\left(\mathrm{TiO}_{2}\right)$ on algae and daphnids," Environmental Science and Pollution Research, vol. 13, no. 4, pp. 225-232, 2006.

[217] L. Zheng, F. Hong, S. Lu, and C. Liu, "Effect of nano-TiO on strength of naturally aged seeds and growth of spinach," Biological Trace Element Research, vol. 104, no. 1, pp. 83-91, 2005.

[218] F. Yang, F. Hong, W. You et al., "Influences of nano-anatase $\mathrm{TiO}_{2}$ on the nitrogen metabolism of growing spinach," Biological Trace Element Research, vol. 110, no. 2, pp. 179-190, 2006.

[219] G. Fengqing, L. Chao, Q. Chunxiang et al., "Was improvement of spinach growth by nano-TiO2 treatment related to the changes of Rubisco activase?" BioMetals, vol. 21, no. 2, pp. 211217, 2008.

[220] T. Han, T. Fan, S. Chow, and D. Zhang, "Biogenic N-Pcodoped $\mathrm{TiO}_{2}$ : synthesis, characterization and photocatalytic properties," Bioresource Technology, vol. 101, no. 17, pp. 6829$6835,2010$. 
[221] A. Foltête, J. Masfaraud, E. Bigorgne et al., "Environmental impact of sunscreen nanomaterials: ecotoxicity and genotoxicity of altered $\mathrm{TiO}_{2}$ nanocomposites on Vicia faba," Environmental Pollution, vol. 159, no. 10, pp. 2515-2522, 2011.

[222] W. Xie, H. Wang, and H. Li, "Silica-supported tin oxides as heterogeneous acid catalysts for transesterification of soybean oil with methanol," Industrial and Engineering Chemistry Research, vol. 51, no. 1, pp. 225-231, 2012.

[223] L. Molina-Barahona, L. Vega-Loyo, M. Guerrero et al., "Ecotoxicological evaluation of diesel-contaminated soil before and after a bioremediation process," Environmental Toxicology, vol. 20, no. 1, pp. 100-109, 2005.

[224] F. P. C. Blamey, D. G. Edwards, and C. J. Asher, "Effects of aluminum, $\mathrm{OH}: \mathrm{Al}$ and $\mathrm{P}: \mathrm{Al}$ molar ratios, and ionic strength on soybean root elongation in solution culture," Soil Science, vol. 136, no. 4, pp. 197-207, 1983.

[225] M. Kollmeier, H. H. Felle, and W. J. Horst, "Genotypical differences in aluminum resistance of maize are expressed in the distal part of the transition zone. Is reduced basipetal auxin flow involved in inhibition of root elongation by aluminum?" Plant Physiology, vol. 122, no. 3, pp. 945-956, 2000.

[226] Y. Yamamoto, Y. Kobayashi, and H. Matsumoto, "Lipid peroxidation is an early symptom triggered by aluminum, but not the primary cause of elongation inhibition in Pea roots," Plant Physiology, vol. 125, no. 1, pp. 199-208, 2001.

[227] Q. Tian, D. Sun, M. Zhao, and W. Zhang, "Inhibition of nitric oxide synthase (NOS) underlies aluminum-induced inhibition of root elongation in Hibiscus moscheutos," New Phytologist, vol. 174, no. 2, pp. 322-331, 2007.

[228] P. R. Ryan, J. E. Shaff, and L. V. Kochian, "Aluminum toxicity in roots: correlation among ionic currents, ion fluxes, and root elongation in aluminum-sensitive and aluminum-tolerant wheat cultivars," Plant Physiology, vol. 99, no. 3, pp. 1193-1200, 1992.

[229] J. B. Sartain and E. J. Kamprath, "Aluminum tolerance of soybean cultivars based on root elongation in solution culture compared with growth in acid soil," Argonomy Journal, vol. 70, no. 1, pp. 17-20, 1978.

[230] T. B. Kinraide, P. R. Ryan, and L. V. Kochian, "Interactive effects of $\mathrm{Al}^{3+}, \mathrm{H}^{+}$, and other cations on root elongation considered in terms of cell-surface electrical potential," Plant Physiology, vol. 99, no. 4, pp. 1461-1468, 1992.

[231] R. C. Jonanthan, B. C. Anne, and J. T. Gregory, "Patterns of root respiration associated with the induction of aluminium tolerance in Phaseolus vulgaris L.," Journal of Experiment Botany, vol. 43, no. 8, pp. 1075-1081, 1992.

[232] P. A. A. Pereira and F. A. Bliss, "Nitrogen fixation and plant growth of common bean (Phaseolus vulgaris L.) at different levels of phosphorus availability," Plant and Soil, vol. 104, no. 1, pp. 79-84, 1987.

[233] D. B. Lazof and M. J. Holland, "Evaluation of the aluminiuminduced root growth inhibition in isolation from low $\mathrm{pH}$ effects in Glycine max, Pisum sativum and Phaseolus vulgaris," Australian Journal of Plant Physiology, vol. 26, no. 2, pp. 147-157, 1999.

[234] A. F. Rangel, I. M. Rao, and W. J. Horst, "Spatial aluminium sensitivity of root apices of two common bean (Phaseolus vulgaris L.) genotypes with contrasting aluminium resistance," The Journal of Experimental Botany, vol. 58, no. 14, pp. 38953904, 2007.
[235] L. V. Kochian, "Cellular mechanisms of aluminum toxicity and resistance in plants," Annual Review of Plant Physiology and Plant Molecular Biology, vol. 46, pp. 237-260, 1995.

[236] H. Matsumoto, "Cell biology of aluminum toxicity tolerance in higher plants," International Review of Cytology, vol. 200, pp. 146, 2000.

[237] D. F. Charles, "Plant adaptation to acid, aluminum-toxic soils," Communications in Soil Science and Plant Analysis, vol. 19, no. 7, 1988.

[238] V. K. Leon, A. P. Miguel, and A. H. Owen, "The physiology, genetics and molecular biology of plant aluminum resistance and toxicity," in Root Physiology: From Gene to Function, vol. 4 of Plant Ecophysiology, pp. 175-195, 2005.

[239] W. Hartley, R. Edwards, and N. W. Lepp, "Arsenic and heavy metal mobility in iron oxide-amended contaminated soils as evaluated by short- and long-term leaching tests," Environmental Pollution, vol. 131, no. 3, pp. 495-504, 2004.

[240] H. Zhu, J. Han, J. Q. Xiao, and Y. Jin, “Uptake, translocation, and accumulation of manufactured iron oxide nanoparticles by pumpkin plants," Journal of Environmental Monitoring, vol. 10, no. 6, pp. 713-717, 2008.

[241] A. Besson-Bard, A. Gravot, P. Richaud et al., "Nitric oxide contributes to cadmium toxicity in arabidopsis by promoting cadmium accumulation in roots and by up-regulating genes related to iron uptake," Plant Physiology, vol. 149, no. 3, pp. 1302$1315,2009$.

[242] W. G. Sunda and S. A. Huntsman, "Iron uptake and growth limitation in oceanic and coastal phytoplankton," Marine Chemistry, vol. 50, no. 1-4, pp. 189-206, 1995.

[243] M. K. Stephan, "Iron oxide dissolution and solubility in the presence of siderophores," Aquatic Sciences, vol. 66, no. 1, pp. 3-18, 2004.

[244] H. J. Laanbroek, "Bacterial cycling of minerals that affect plant growth in waterlogged soils: a review," Aquatic Botany, vol. 38, no. 1, pp. 109-125, 1990.

[245] W. Hartley and N. W. Lepp, "Remediation of arsenic contaminated soils by iron-oxide application, evaluated in terms of plant productivity, arsenic and phytotoxic metal uptake," Science of the Total Environment, vol. 390, no. 1, pp. 35-44, 2008.

[246] A. R. John, "The iron and molybdenum use efficiencies of plant growth with different energy, carbon and nitrogen sources," New Phytologist, vol. 109, no. 3, pp. 279-287, 1988.

[247] M. Becana, J. F. Moran, and I. Iturbe-Ormaetxe, "Irondependent oxygen free radical generation in plants subjected to environmental stress: toxicity and antioxidant protection," Plant and Soil, vol. 201, no. 1, pp. 137-147, 1998.

[248] M. S. Green and J. R. Etherington, "Oxidation of ferrous iron by rice (Oryza sativa L.) roots: a mechanism for waterlogging tolerance?" The Journal of Experimental Botany, vol. 28, no. 3, pp. 678-690, 1977.

[249] C. C. Chen, J. B. Dixon, and F. T. Turner, "Iron coatings on rice roots: morphology and models of development," Soil Science Society of America Journal, vol. 44, no. 5, pp. 1113-1119, 1979.

[250] A. K. Ioannis and I. Z. Anastasios, "Removal of arsenic from contaminated water sources by sorption onto iron-oxide-coated polymeric materials," Water Research, vol. 36 , no. 20, pp. 5141$5155,2002$.

[251] M. Mahmoudi, M. A. Shokrgozar, A. Simchi et al., "Multiphysics flow modeling and in vitro toxicity of iron oxide nanoparticles coated with poly(vinyl alcohol)," Journal of Physical Chemistry C, vol. 113, no. 6, pp. 2322-2331, 2009. 
[252] E. Lombi, W. W. Wenzel, and R. S. Sletten, "Arsenic adsorption by soils and iron-oxide-coated sand: kinetics and reversibility," Journal of Plant Nutrition and Soil Science, vol. 162, no. 4, pp. 451-456, 1999.

[253] A. S. Greipsson and A. Crowder, "Amelioration of copper and nickel toxicity by iron plaque on roots of rice (Oryza sativa)," Canadian Journal of Botany, vol. 70, no. 4, pp. 1-10, 1992.

[254] B. D. Wheeler, M. M. Al-Farraj, and R. E. D. Cook, "Iron toxicity to plants in base-rich wetlands: comparative effects on the distribution and growth of Epilobium hirsutum L. and Juncus subnodulosus, Schrank," New Phytologist, vol.100, no. 4, pp. 653669, 1985.

[255] W. J. Liu, Y. G. Zhu, Y. Hu et al., "Arsenic sequestration in iron plaque, its accumulation and speciation in mature rice plants (Oryza Sativa L.)," Environmental Science and Technology, vol. 40, no. 18, pp. 5730-5736, 2006.

[256] A. J. P. Smolders and J. G. M. Roelofs, "The roles of internal iron hydroxide precipitation, sulphide toxicity and oxidizing ability in the survival of Stratiotes aloides roots at different iron concentrations in sediment pore water," New Phytologist, vol. 133, no. 2, pp. 253-260, 1996.

[257] Y. Ma, L. Kuang, X. He et al., "Effects of rare earth oxide nanoparticles on root elongation of plants," Chemosphere, vol. 78, no. 3, pp. 273-279, 2010.

[258] K. M. Reddy, K. Feris, J. Bell, D. G. Wingett, C. Hanley, and A. Punnoose, "Selective toxicity of zinc oxide nanoparticles to prokaryotic and eukaryotic systems," Applied Physics Letters, vol. 90, no. 21, Article ID 213902, 2007.

[259] W. Bai, Z. Zhang, W. Tian et al., "Toxicity of zinc oxide nanoparticles to zebrafish embryo: a physicochemical study of toxicity mechanism," Journal of Nanoparticle Research, vol. 12, no. 5, pp. 1645-1654, 2010.

[260] W. Y. W. Stella, T. Y. L. Priscilla, A.B. Djurišić, and M. Y. L. Kenneth, "Toxicities of nano zinc oxide to five marine organisms: influences of aggregate size and ion solubility," Analytical and Bioanalytical Chemistry, vol. 396, no. 2, pp. 609618,2010

[261] H. Ma, P. M. Bertsch, T. C. Glenn, N. J. Kabengi, and P. L. Williams, "Toxicity of manufactured zinc oxide nanoparticles in the nematode Caenorhabditis elegans," Environmental Toxicology and Chemistry, vol. 28, no. 6, pp. 1324-1330, 2009.

[262] F.-M. Huang, K.-W. Tai, M.-Y. Chou, and Y.-C. Chang, "Cytotoxicity of resin-, zinc oxide-eugenol-, and calcium hydroxidebased root canal sealers on human periodontal ligament cells and permanent V79 cells," International Endodontic Journal, vol. 35, no. 2, pp. 153-158, 2002.

[263] V. Sharma, R. K. Shukla, N. Saxena, D. Parmar, M. Das, and A. Dhawan, "DNA damaging potential of zinc oxide nanoparticles in human epidermal cells," Toxicology Letters, vol. 185, no. 3, pp. 211-218, 2009.

[264] I. Y. R. Adamson, H. Prieditis, C. Hedgecock, and R. Vincent, "Zinc is the toxic factor in the lung response to an atmospheric particulate sample," Toxicology and Applied Pharmacology, vol. 166, no. 2, pp. 111-119, 2000.

[265] M. Z. Bin Hussein, Z. Zainal, A. H. Yahaya, and D. W. V. Foo, "Controlled release of a plant growth regulator, $\alpha$ naphthaleneacetate from the lamella of Zn-Al-layered double hydroxide nanocomposite," Journal of Controlled Release, vol. 82, no. 2-3, pp. 417-427, 2002.

[266] X. Wang, C. J. Summers, and Z. L. Wang, "Large-scale hexagonal-patterned growth of aligned $\mathrm{ZnO}$ nanorods for nano-optoelectronics and nanosensor arrays," Nano Letters, vol. 4, no. 3, pp. 423-426, 2004.

[267] R. S. Dwivedi and N. S. Randhawa, "Evaluation of a rapid test for the hidden hunger of zinc in plants," Plant and Soil, vol. 40, no. 2, pp. 445-451, 1974.

[268] J. F. Loneragan, T. S. Grove, A. D. Robson, and K. Snowball, "Phosphorus toxicity as a factor in zinc-phosphorus interactions in plants," American Society of Agronomy, vol. 43, no. 5, pp. 966-972, 1978.

[269] G. Fiskesjo, "Allium Test I: A 2-3 day plant test for toxicity assessment by measuring the mean root growth of onions (Allium cepa L.)," Environmental Toxicology and Water Quality, vol. 8, no. 4, pp. 461-470, 1993.

[270] M. B. Arambašić, S. Bjelić, and G. Subakov, "Acute toxicity of heavy metals (copper, lead, zinc), phenol and sodium on Allium cepa L., Lepidium sativum L. and Daphnia magna St.: comparative investigations and the practical applications," Water Research, vol. 29, no. 2, pp. 497-503, 1995.

[271] R. Geremias, D. Fattorini, V. T. D. Fávere, and R. C. Pedrosa, "Bioaccumulation and toxic effects of copper in common onion Allium cepa L.," Chemistry and Ecology, vol. 26, no. 1, pp. 19-26, 2010.

[272] W. Lee, Y. An, H. Yoon, and H. Kweon, "Toxicity and bioavailability of copper nanoparticles to the terrestrial plants mung bean (Phaseolus radiatus) and wheat (Triticum aestivum): plant agar test for water-insoluble nanoparticles," Environmental Toxicology and Chemistry, vol. 27, no. 9, pp. 1915-1921, 2008.

[273] G. J. Taylor and C. D. Foy, "Differential uptake and toxicity of ionic and chelated copper in Triticum aestivum," Canadian Journal of Botany, vol. 63, no. 7, pp. 1271-1275, 1985.

[274] O. Munzuroglu and H. Geckil, "Effects of metals on seed germination, root elongation, and coleoptile and hypocotyl growth in Triticum aestivum and Cucumis sativus," Archives of Environmental Contamination and Toxicology, vol. 43, no. 2, pp. 203-213, 2002.

[275] M. Wang and Q. Zhou, "Single and joint toxicity of chlorimuron-ethyl, cadmium, and copper acting on wheat Triticum aestivum," Ecotoxicology and Environmental Safety, vol. 60, no. 2, pp. 169-175, 2005.

[276] W. G. Keltjens and M. L. Van Beusichem, "Phytochelatins as biomarkers for heavy metal stress in maize (Zea mays L.) and wheat (Triticum aestivum L.): combined effects of copper and cadmium," Plant and Soil, vol. 203, no. 1, pp. 119-126, 1998.

[277] R. Chandra, R. N. Bharagava, S. Yadav, and D. Mohan, "Accumulation and distribution of toxic metals in wheat (Triticum aestivum L.) and Indian mustard (Brassica campestris L.) irrigated with distillery and tannery effluents," Journal of Hazardous Materials, vol. 162, no. 2-3, pp. 1514-1521, 2009.

[278] F. H. Tani and S. Barrington, "Zinc and copper uptake by plants under two transpiration rates. Part I. Wheat (Triticum aestivum L.)." Environmental Pollution, vol. 138, no. 3, pp. 538-547, 2005.

[279] Y. An, "Assessment of comparative toxicities of lead and copper using plant assay," Chemosphere, vol. 62, no. 8, pp. 1359-1365, 2006.

[280] B. Mocquot, J. Vangronsveld, H. Clijsters, and M. Mench, "Copper toxicity in young maize (Zea mays L.) plants: effects on growth, mineral and chlorophyll contents, and enzyme activities," Plant and Soil, vol. 182, no. 2, pp. 287-300, 1996.

[281] L. Lombardi and L. Sebastiani, "Copper toxicity in Prunuscerasifera: growth and antioxidant enzymes responses of in vitro grown plants," Plant Science, vol. 168, no. 3, pp. 797-802, 2005. 
[282] J. E. J. Weckx and H. M. M. Clijsters, "Oxidative damage and defense mechanisms in primary leaves of Phaseolus vulgaris as a result of root assimilation of toxic amounts of copper," Physiologia Plantarum, vol. 96, no. 3, pp. 506-512, 1996.

[283] M. L. López-Moreno, G. de la Rosa, J. A. Hernández-Viezcas, J. R. Peralta-Videa, and J. L. Gardea-Torresdey, "X-ray absorption spectroscopy (XAS) corroboration of the uptake and storage of $\mathrm{CeO}_{2}$ nanoparticles and assessment of their differential toxicity in four edible plant species," Journal of Agricultural and Food Chemistry, vol. 58, no. 6, pp. 3689-3693, 2010.

[284] J. A. Hernandez-Viezcas, H. Castillo-Michel, J. C. Andrews et al., "In situ synchrotron X-ray fluorescence mapping and speciation of $\mathrm{CeO}_{2}$ and $\mathrm{ZnO}$ nanoparticles in soil cultivated soybean (Glycine max)," ACS Nano, vol. 7, no. 2, pp. 1415-1423, 2013.

[285] F. Torney, B. G. Trewyn, V. S.-Y. Lin, and K. Wang, "Mesoporous silica nanoparticles deliver DNA and chemicals into plants," Nature Nanotechnology, vol. 2, no. 5, pp. 295-300, 2007.

[286] H. A. Currie and C. C. Perry, "Silica in plants: biological, biochemical and chemical studies," Annals of Botany, vol. 100, no. 7, pp. 1383-1389, 2007.

[287] I. Fenoglio, A. Croce, F. di Renzo, R. Tiozzo, and B. Fubini, "Pure-silica zeolites (porosils) as model solids for the evaluation of the physicochemical features determining silica," Chemical Research in Toxicology, vol. 13, no. 6, pp. 489-500, 2000.

[288] M. Pola, L. C. Tamara, and T. H. Andrew, "Toxicity, uptake, and translocation of engineered nanomaterials in vascular plants," Environmental Science and Technology, vol. 46, no. 17, pp. 92249239, 2012.

[289] K. Birbaum, R. Brogioli, M. Schellenberg et al., "No evidence for cerium dioxide nanoparticle translocation in maize plants," Environmental Science and Technology, vol. 44, no. 22, pp. 87188723, 2010.

[290] S. Lin, J. Reppert, Q. Hu et al., "Uptake, translocation, and transmission of carbon nanomaterials in rice plants," Small, vol. 5, no. 10, pp. 1128-1132, 2009.

[291] L. Zhang, C. Feng, Z. Chen et al., "Superaligned carbon nanotube grid for high resolution transmission electron microscopy of nanomaterials," Nano Letters, vol. 8, no. 8, pp. 2564-2569, 2008.

[292] F. Sharif, P. Westerhoff, and P. Herckes, "Sorption of trace organics and engineered nanomaterials onto wetland plant material," Environmental Sciences: Processes and Impacts, vol. 15, no. 1, pp. 267-274, 2013.

[293] R. Nair, M. S. Mohamed, W. Gao et al., "Effect of carbon nanomaterials on the germination and growth of rice plants," Journal of Nanoscience and Nanotechnology, vol. 12, no. 3, pp. 2212-2220, 2012.

[294] G. Abdi, H. Salehi, and M. Khosh-Khui, "Nano silver: a novel nanomaterial for removal of bacterial contaminants in valerian (Valeriana officinalis L.) tissue culture," Acta Physiologiae Plantarum, vol. 30, no. 5, pp. 709-714, 2008.

[295] X. Ma, J. Geiser-Lee, Y. Deng, and A. Kolmakov, "Interactions between engineered nanoparticles (ENPs) and plants: phytotoxicity, uptake and accumulation," Science of the Total Environment, vol. 408, no. 16, pp. 3053-3061, 2010. 

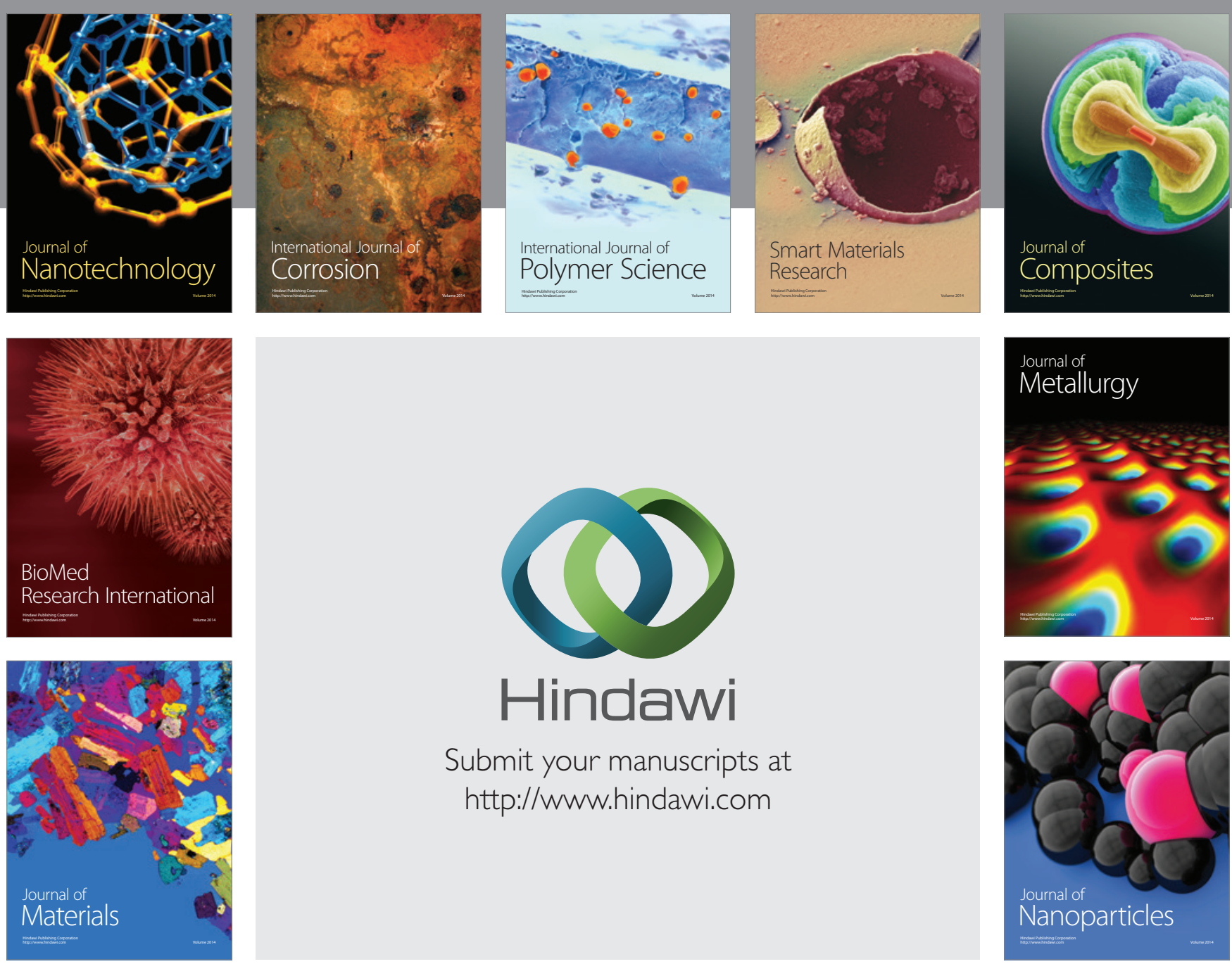

Submit your manuscripts at http://www.hindawi.com
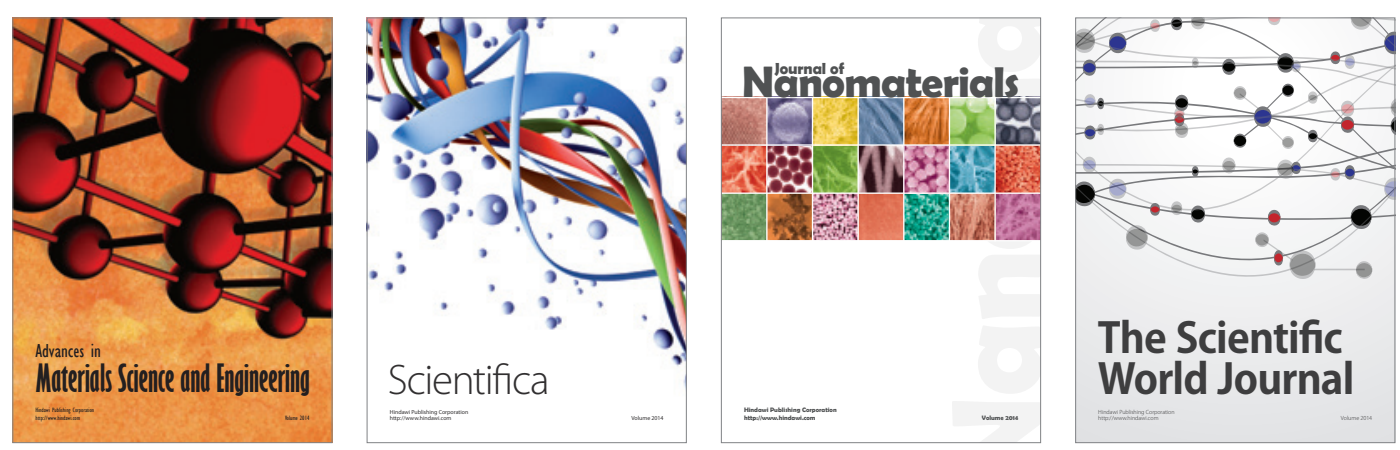

\section{The Scientific World Journal}
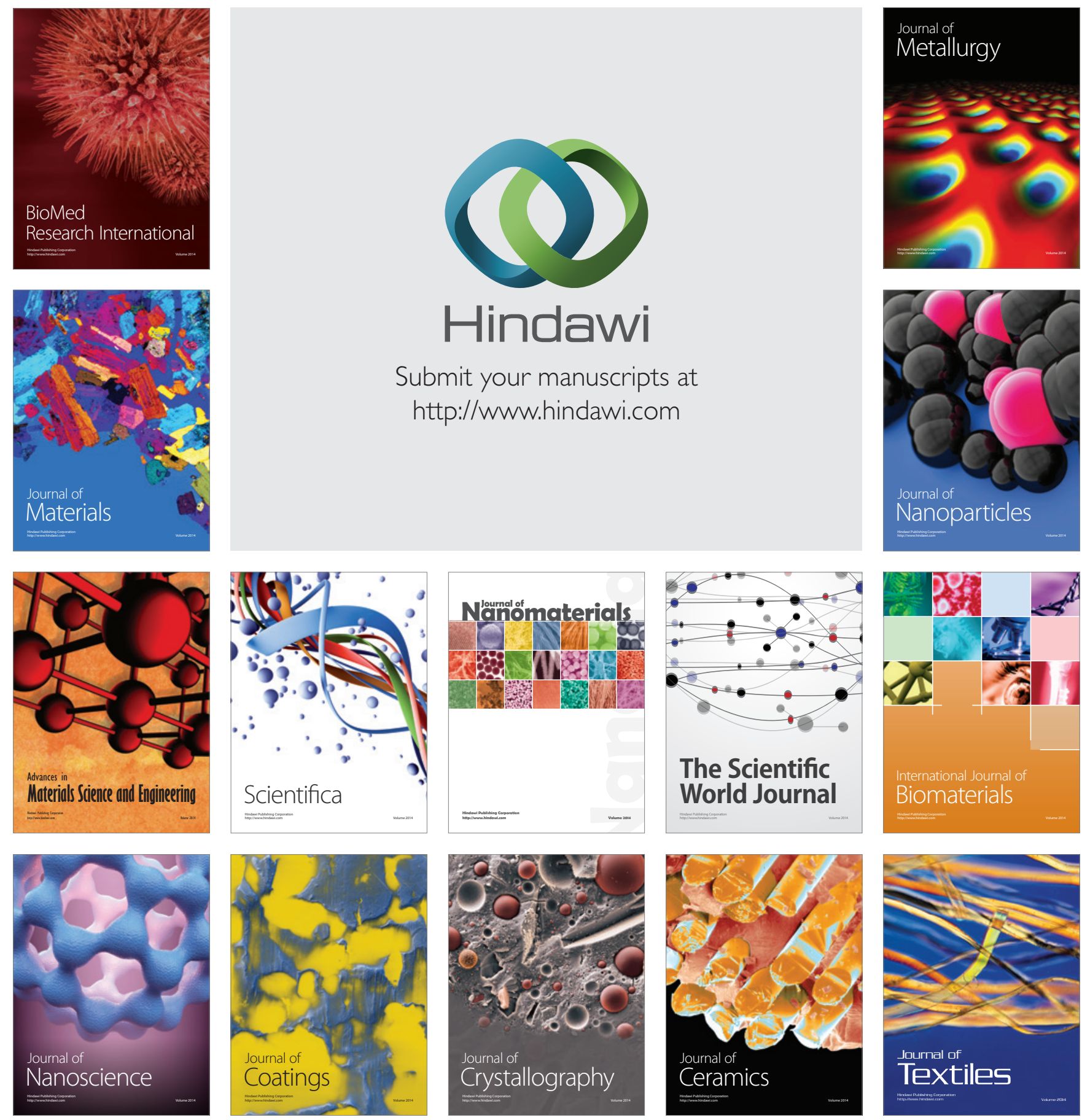